\title{
Conversion of
}

Forest Residues to a

Methane-Rich Gas

\author{
Interim Report
}

March 1986

Prepared by Battelle Columbus Laboratories

for Pacific Northwest Laboratory

under Contract DE-AC06-76RLO 1830

with the U.S. Department of Energy

Pacific Northwest Laboratory

Operated for the U.S. Department of Energy

by Battelle Memorial Institute 


\title{
DISCLAIMER
}

This report was prepared as an account of work sponsored by an agency of the United States Government. Neither the United States Government nor any agency thereof, nor any of their employees, makes any warranty, express or implied, or assumes any legal liability or responsibility for the accuracy, completeness, or usefulness of any information, apparatus, product, or process disclosed, or represents that its use would not infringe privately owned rights. Reference herein to any specific commercial product, process, or service by trade name, trademark, manufacturer, or otherwise, does not necessarily constitute or imply its endorsement, recommendation, or favoring by the United States Government or any agency thereof. The views and opinions of authors expressed herein do not necessarily state or reflect those of the United States Government or any agency thereof.

\author{
PACIFIC NORTHWEST LABORATORY \\ operated by \\ BATTELLE \\ for the \\ UNITED STATES DEPARTMENT OF ENERGY \\ under Contract DE-AC06-76RLO 1830
}

\begin{tabular}{|c|c|}
\hline \multicolumn{2}{|c|}{ Printed in the United States of America } \\
\hline \multicolumn{2}{|c|}{ Available from } \\
\hline \multirow{2}{*}{\multicolumn{2}{|c|}{$\begin{array}{l}\text { National Technical Information Service } \\
\text { United States Department of Commerce }\end{array}$}} \\
\hline & \\
\hline \multicolumn{2}{|c|}{5285 Port Royal Road } \\
\hline \multicolumn{2}{|c|}{ Springfield, Virginia 22161} \\
\hline \multicolumn{2}{|c|}{ NTIS Price Codes } \\
\hline \multicolumn{2}{|c|}{ Microfiche A01 } \\
\hline \multicolumn{2}{|c|}{ Printed Copy } \\
\hline & Price \\
\hline Pages & Codes \\
\hline $001-025$ & A02 \\
\hline 026-050 & $\mathrm{A03}$ \\
\hline $051-075$ & A04 \\
\hline $076-100$ & A05 \\
\hline $101-125$ & $A 06$ \\
\hline $126-150$ & A07 \\
\hline 151.175 & $A 0 B$ \\
\hline $176-200$ & $\mathrm{~A} 09$ \\
\hline $201-225$ & A010 \\
\hline $226-250$ & A011 \\
\hline $251-275$ & A012 \\
\hline $276-300$ & A013 \\
\hline
\end{tabular}


H. G. Feldmann

M. A. Paisley

H. R. Appelbaum

Battelle Colımbus Lahoratories

Columbus, Ohio

March 1986

Prepared hy Battelle Columbus Laboratories for Pacific Northwest Laboratory under Contract DE-AC06-76RL0 1830

with the IJ.S. Department of Energy

Pacific Northwest Laboratory

Richland, washington 99352 
-

$+$

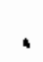


A process is being developed that produces a fuel gas with a heating value of $500 \mathrm{Btu} / \mathrm{SCF}$ from diverse forms of biomass, including shredded bark, wood chips, and sawdust. The system uses a high throughput, non-oxygen gasifier that employs sand circulation to supply process heat.

Results obtained with a 10-inch I.D. gasifier are presented and compared with those in a 6 -inch $I, 0$. reactor. Feed rates up to 12 tons/day (dry) have been achieved corresponding to a specific wood throughput of $2,000 \mathrm{ibs} / \mathrm{ft} \mathrm{t}^{2}-\mathrm{hr}$. Gas compositions in the two reactors are in excellent agreement and performance in the larger reactor, as measured by carbon conversion, is significantly improved. Cost projections comparing this process with direct combustion are presented that indicate gasification technology should have very signi ficant cost advantages for both generation of plant steam and cogeneration of electricity. 
*

- 


\section{CONTENTS}

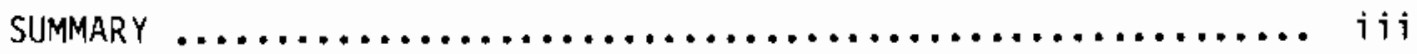

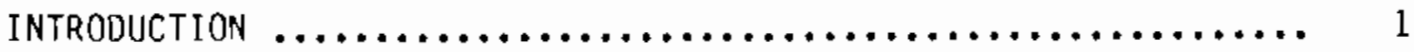

SUMMARY OF PROGRAM ACCOMPLISHMENTS MARCH 1983 -

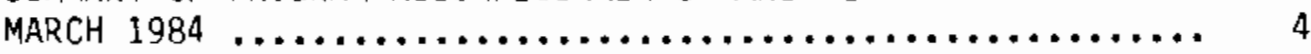

Unit Modifications $\ldots \ldots \ldots \ldots \ldots \ldots \ldots \ldots \ldots \ldots \ldots \ldots$

Experimental Results ....................... 4

Process Engineering Support $\ldots \ldots \ldots \ldots \ldots \ldots \ldots \ldots \ldots \ldots$

Technology Transfer $\ldots \ldots \ldots \ldots \ldots \ldots \ldots \ldots \ldots \ldots \ldots \ldots$

UNIT MODIFICATIONS $\ldots \ldots \ldots \ldots \ldots \ldots \ldots \ldots \ldots \ldots \ldots \ldots \ldots \ldots$

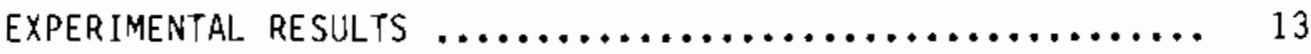

Baseline Mode Tests .......................... 19

Tests in the Modified Gasifier .................. 19

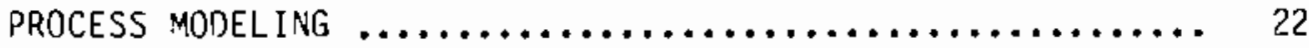

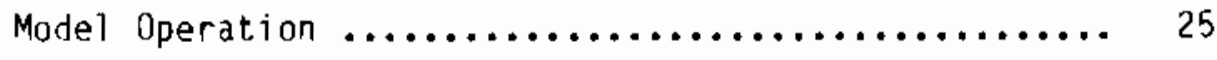

ECONOMIC EVALUATION $\ldots \ldots \ldots \ldots \ldots \ldots \ldots \ldots \ldots \ldots \ldots \ldots . \ldots \ldots$

Direct Combustion Versus Gasification-Cost

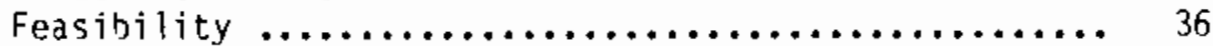

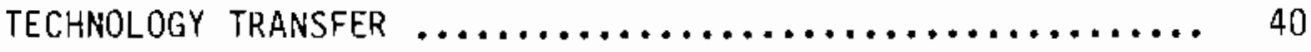

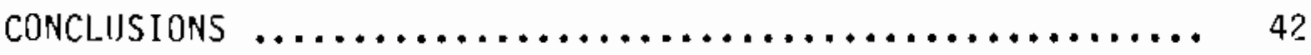

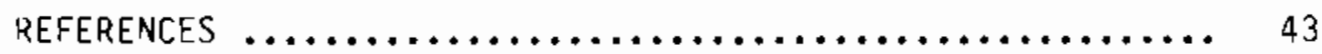


1$$
\text { . }
$$ 


\section{FIGURES}

1. BATTELLE'S BIOMASS GASIFICATION SYSTEM $\ldots \ldots \ldots \ldots \ldots \ldots \ldots, 2$

2. BATTELLE'S BIOMASS GASIFICATION PRIJ $\ldots \ldots \ldots \ldots \ldots \ldots \ldots . .$.

3. PHOTO OF BATTELLE.' S GASIFICATION PRU $\ldots \ldots \ldots \ldots \ldots \ldots \ldots, 10$

4. SCHEMATIC OF FEED SYSTEM $\ldots \ldots \ldots \ldots \ldots \ldots \ldots \ldots \ldots \ldots \ldots, 11$

5. FORMS OF FEEO MATERIALS $\ldots \ldots \ldots \ldots \ldots \ldots \ldots \ldots \ldots \ldots \ldots \ldots \ldots \ldots, 1$.

6. BATTELLE'S BIOMASS GASIFICATION $\ldots \ldots \ldots \ldots \ldots \ldots \ldots \ldots \ldots, 20$

7. BATTELLE'S BIOMASS GASIFICATION $\ldots \ldots \ldots \ldots \ldots \ldots \ldots \ldots \ldots \ldots \ldots \ldots \ldots \ldots$

8. PRODUCT GAS HEATING VALUE VARIES SIGNIFICANTLY WITH fEEO MOISTURE IN AN AIR BLOWN SYSTEM .................. 24

9. BATTELLE'S BIOMASS GASIFICATION COMPUTER MODEL $\ldots \ldots \ldots \ldots .27$

10. MASS ANO ENERGY BALANCE SUMMARY FOR FOREST RESIDUE

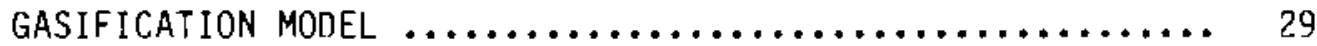

11. MASS AND ENERGY BALANCE FOR A 200 TPD PLANT USING SOFTWOOD AS THE FEEDSTOCK $\ldots \ldots \ldots \ldots \ldots \ldots \ldots \ldots \ldots \ldots \ldots, 31$

12. HEAT LOSS INCREASES SIGNIFICANTLY IN SMALLER FACTORS $\ldots . . .34$

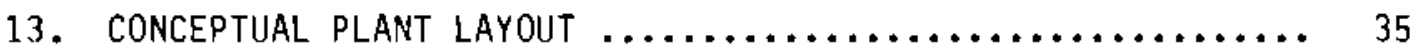

14. NEW TECHNOLOGY RESULTS IN MORE COMPACT EOUIPMENT $\ldots \ldots \ldots \ldots .39$ TABLES

1. DATA gENERATED DURING CURRENT PRDGRAM PHASE $\ldots \ldots \ldots \ldots \ldots, 14$

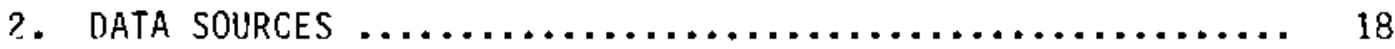

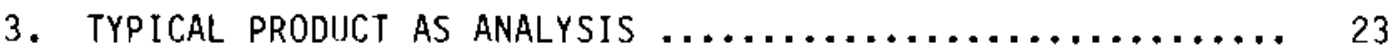

4. GASIFICATION VERSUS DIRECT COMBUSTION FOR STEAM

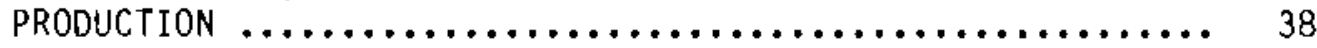

5. GASIFICATION VERSUS DIRECT COMBUSTION FOR COGENERATION .... 41 
1

1)

$\therefore$ , 


\section{INTRODUCTION}

This paper presents results of a program conducted by Battelle's Columbus Laboratories aimed at the use of renewable biomass resources to produce a medium-Btu fuel gas without the use of an oxygen plant. The concept utilizes a high-throughput gasifier capable of handing diverse forms of biomass without pretreatment.

In order to be readily accepted by industry, fuel gas derived from biomass sources must be able to replace oil and natural gas in existing units without significant retrofit expenses. In addition, installations switching from oil or natural gas will no doubt want the capability to continue to use the more traditional fuels in a backup mode. It becomes an important advantage then to produce a gas that can be interchanged with these high energy density fuels with minimum retrofit requirements. In general, this means that the product gas must have a higher heating value of at least $300 \mathrm{Btu} / \mathrm{cu}$. $\mathrm{ft}$. In conventional gasification systems, this would require oxygen to be used as the oxidant source to avoid nitrogen dilution of the product gas. At the modest scale of typical biomass gasification plants, however, oxygen is ordinarily too expensive to produce a competitively priced product gas. The Battelle gasifier overcomes this limitation by supplying the heat from an external circulating phase, thus, producing a medium Btu gas without requiring an oxygen plant.

A schematic flowsheet of the gasification process under development at Battelle's Columbus Laboratories is found in Figure 1. The process employs a hot sand phase as a conveying and heat transfer medium. By use of such heat transfer methods, it is possible to produce a $500 \mathrm{Btu} / \mathrm{SCF}$ fuel gas from biomass without using oxygen. Wood is fed into the gasifier with no pretreatment except partial drying to utilize sensible heat present in the flue gas from the combustor. The wood (or other biomass) is gasified at throughputs up to $2000 \mathrm{lb} / \mathrm{hr}-\mathrm{ft}^{2}$ of reactor area to produce the fuel gas and a small quantity of char 


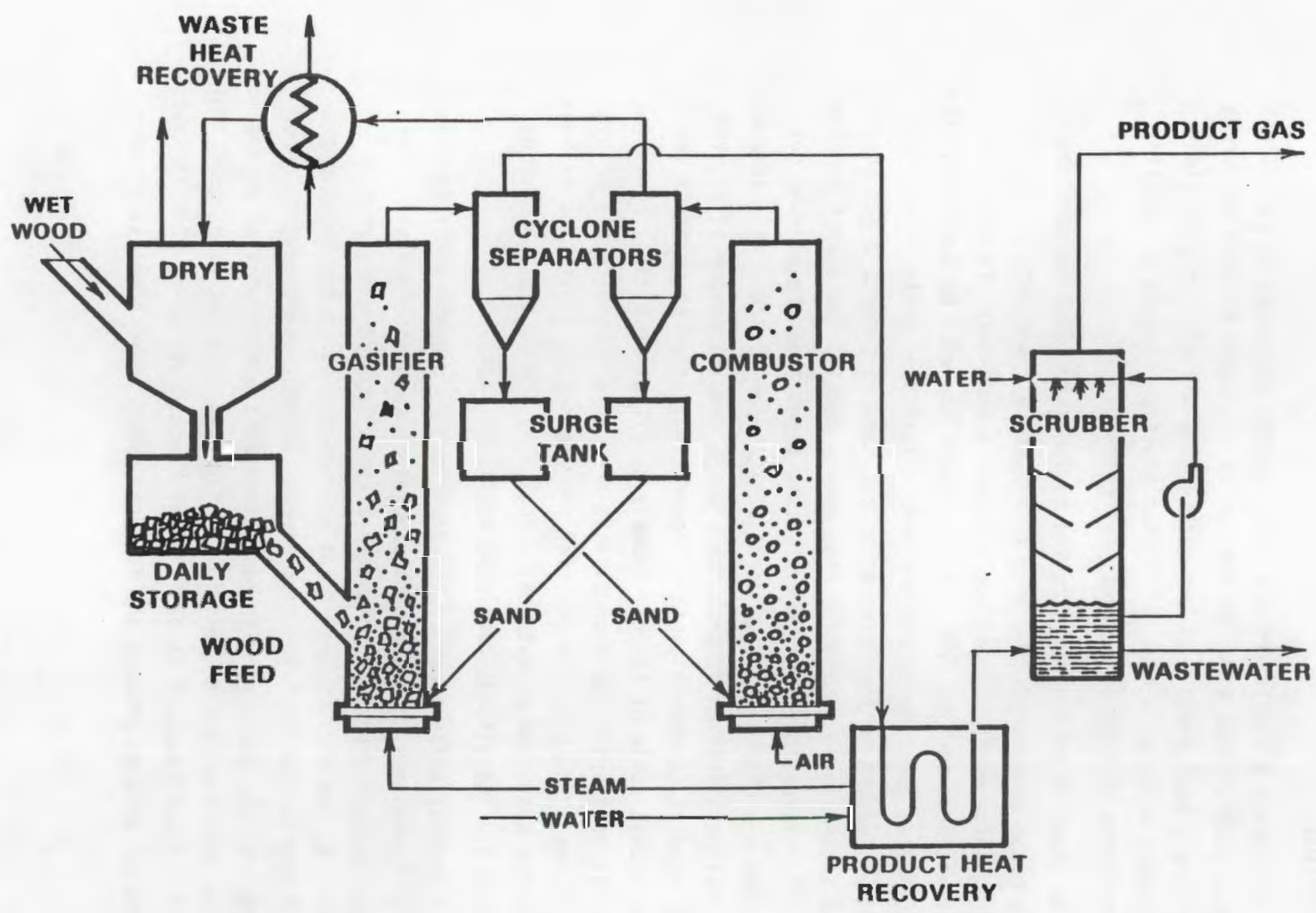

FIGURE 1. BATTELLE'S BIOMASS GASIFICATION SYSTEM 
(typically 20 percent of the dry wood fed). The char and sand then are removed from the gas phase and transferred to the combustor, where the char is burned. The combustion reactions reheat the sand, which returns to the gasifier to provide the heat for gasification.

Heat recovery from product and flue gases provides both process and export steam (or other heat sources as might be needed) in addition to drying incoming wood.

Separation of the gasification and combustion zones allows the following two major advantages.

(1) Medium-Btu gas can be produced without requiring an oxygen plant-which is expensive at the scale of most biomass gasification plants.

(2) The heating value of the cooled cleaned product gas remains constant, independent of the moisture level of the feed.

Early testing of the process was conducted in a $250 \mathrm{ib} / \mathrm{hr}$ process research unit (PRU) at Battelle's Columbus Labortories. (1) These tests demonstrated the major virtues of this process approach were:

- A medium Btu (400 $\longrightarrow 500 \mathrm{Btu} / \mathrm{SCF}$ ) product gas could be produced from wood without requiring an oxygen plant.

- A wide range of feedstocks could be handled without pretreatment.

- Constant heating value gas can be produced regardless of feed moisture level.

- Extremely high throughputs can be achieved, resulting in compact, economical reactors.

- Heat necessary for gasification can be supplied totally from an entrained, recirculating sand phase.

- No by-product char remains after combustion.

- Tar production is very low with all feedstocks tested.

The success of these initial studies along with favorable economic projections $^{(2)}$ led to the design and modification of the PRU to increase the throughput to 12 tons per day. 
SUMMARY OF PROGRAM ACCOMPLISHMENTS

MARCH 1983 - MARCH 1984

During this period project activities were conducted in the following areas.

(1) Unit Modifications

(2) Process Research Unit (PRU) Experimental Operations

(3) Process Engineering Support

(4) Technology Transfer

The project goals were made or exceeded over this time period and significant accomplishments in each of the above areas are summarized below.

Unit Modifications

Several modifications were made in the PRU to provide data on process scaleability and improve operating efficiency. The initial effort was devoted to testing the "transport wake inducer" (TWI) concept found to greatly improve performance in the 6 inch I.D. gasifier. The specific modifications made are summarized below.

- Instaliation of a 10-jnch I.D. gasifier vessel in place of the existing 6-inch I.D. unit primarily to test process scaleability with and without the TWI's.

- Relining of the combustor to reduce heat losses thereby allowing higher gasification temperatures to be achieved.

- Modification of combustor cyclone to provide a return leg to the combustor to reduce sand losses.

- Increasing the size of the $L$ valve solids circulation circuit between the gasifier and combustor from 3 inches to 4 inches to test $L$ valve scaleability and reduce $\Delta T$ between gasifier and combustor.

- Automating and increasing the capacity of the wood feedsystem.

\section{Experimental Results}

Operation of the 10-inch unit has been smooth and trouble-free and the most significant results achieved in the operation of the 10 -inch I.D. PRU are summarized below. 
- Performance, as measured by carbon conversion, has improved in the 10-inch unit over that achieved in the 6-inch unit. However, unlike the 6-inch unit, no effect of TWIs on performance was noted in the 10-inch unit.

- Gas composition has remained constant.

- Feedstocks tested thus far include:

- Sawdust

- Hardwood Chips

- Softwood Chips

- Throughputs in excess of $2000 \mathrm{lbs} / \mathrm{ft}^{2}-\mathrm{hr}$ (on a dry wood basis) have been achieved. Limitations on feed rate appear to be simply the ability to supply heat with the existing combustor even with the improved lining and other modifications to reduce heat loss.

- Yields of condensible organic liquid products have remained approximately the same between the 6 and 10inch units at approximately $0.5 \mathrm{wt}$. percent of the incoming feed. More work is being done to physically and chemically characterize these liquids to allow efficient gas cleanup systems to be designed.

\section{Process Engineering Support}

- A model has been developed that incorporates experimental data on product distribution, gasifier, and combustor throughputs into a detailed heat and material balance that allows system performance to be estimated as a function of input parameters. This model also provides insight into the interrelationships between process parameters and how the system will respond to "upsets".

- The "base case" conceptual design has been modified and a revised cost estimate made.

\section{Technology Transfer}

- Discussions are being held with potential commercial users of this technology to determine a program for proof-of-concept testing at an industrial site. 
- Riley Stoker is participating in the conceptual design and cost estimation of commercial units and will participate in proof-of-concept scale-up efforts.

\section{UNIT MODIFICATIONS}

The Battelle PRU is an integrated system capable of simulating commercial integrated operation of the gasification/char combustion system. The initial PRU consisted of a 6-inch diameter gasifier, coupled to a 40-inch I.D. refractory lined combustor. The gasifier operates in the high-throughput mode while the PRU combustor is a conventional fluid-bed reactor. The design of the PRU combustor allows it to serve as both a combustor and a surge vessel for the sand phase. The baseline capacity of the 6-inch gasifier was $250 \mathrm{lbs} / \mathrm{hr}$ wood feed, however, wood rates up to $350 \mathrm{lbs} / \mathrm{hr}$ were achieved. (2) This corresponds to a throughput of about $1800 \mathrm{lbs} / \mathrm{hr}-\mathrm{ft}^{2}$ of reactor area.

The rapid heat-up of the wood particles caused by hot sand contacting them results in a rapid evolution of gases. The wood, of course must dry completely prior to any pyrolysis or gasification reactions taking place. For this reason and the fact that residence times in the gasifier are short, it is reasonable to expect that the wood particies remain well below the bulk temperature of the reactor itself.

During previous phases of the program, a modification to increase the contacting of the hot sand and wood was developed. By increasing mixing and residence time in the reactor, it would then be theoretically possible to bring the temperature of the wood closer to the temperature of the hot sand, and thus, increase conversion levels in the gasifier. Such a system was developed and has been referred to as the Controlled Turbulent Zone or CTZ gasifier mode. The controlled turbulent zone concept is made possible by the insertion of proprietary internals into the gasifier called Transport Wake Inducers or TWI's. The TWI's produce zones of highly backmixed solids resulting in increased contacting between wood particles and hot sand. 
The economic implication of this result was reduced investment costs per unit of gas produced. However, since no data base or existing computational models covered scale-up of such a system, it was decided to test the concept in a larger reactor tube to be installed in the existing PRU facility. A 10-inch reactor tube was, therefore, installed and the wood feed system automated to allow operation at the higher wood feed rates required in the larger reactor. The modified PRU is shown schematically in Figure 2 and a photograph of the modified unit is found in Figure 3.

In modifying the gasifier vessel, it was decided to retain the bare metal wall construction in order to decrease the time necessary to change from one steady-state condition to another. The reactor walls are a high-nickel alloy surrounded by electric heating elements sized to balance heat losses from the reactor.

Details of the 10-inch gasifier construction are essentially the same as the 6 -inch gasifier. These have been discussed previously. The PRU combustor is a conventional fluid bed reactor capable of burning natural gas to provide heat for gasification and compensate for system heat losses.

The modifications that were made retained the capability of the PRU to operate at high wood throughputs $\left(2000 \mathrm{lb} / \mathrm{hr}^{-}-\mathrm{ft}^{2}\right)$, and in fact, the feed capacity of the modified PRU was increased to allow even higher throughputs to be evaluated in future tests. With the modifications complete, the system was made capable of totally automatic operation. This allows much higher wood feed rates to be achieved without the limitations of manual wood loading as had been the case in the 6-inch unit. In order to achieve the continuous feed rates needed, the capability to feed wood from outside storage on a continuous basis had to be added. Previously, wood was loaded in drums and transferred to the feeder manually. Due to the low inherent bulk density of wood, however, this is not a feasible approach for wood rates above about 300 $\mathrm{lbs} / \mathrm{hr}$. For the 10-inch unit, therefore, it became necessary to feed the wood pneumatically into the feeder. Referring to Figure 2, wood is augered from an outside storage bin into the air intake of an air blower. 
$\infty$

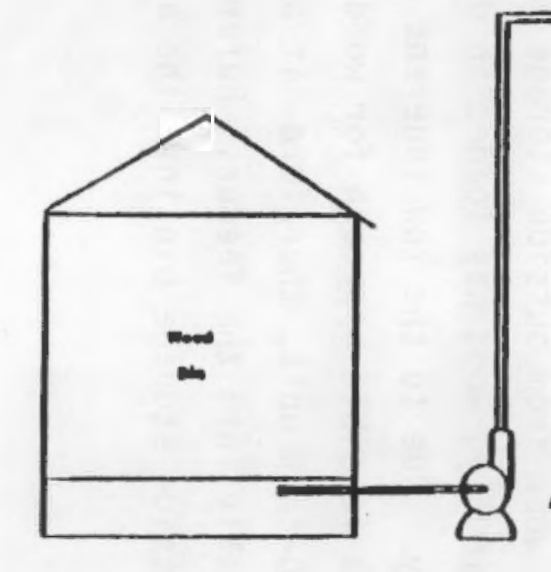

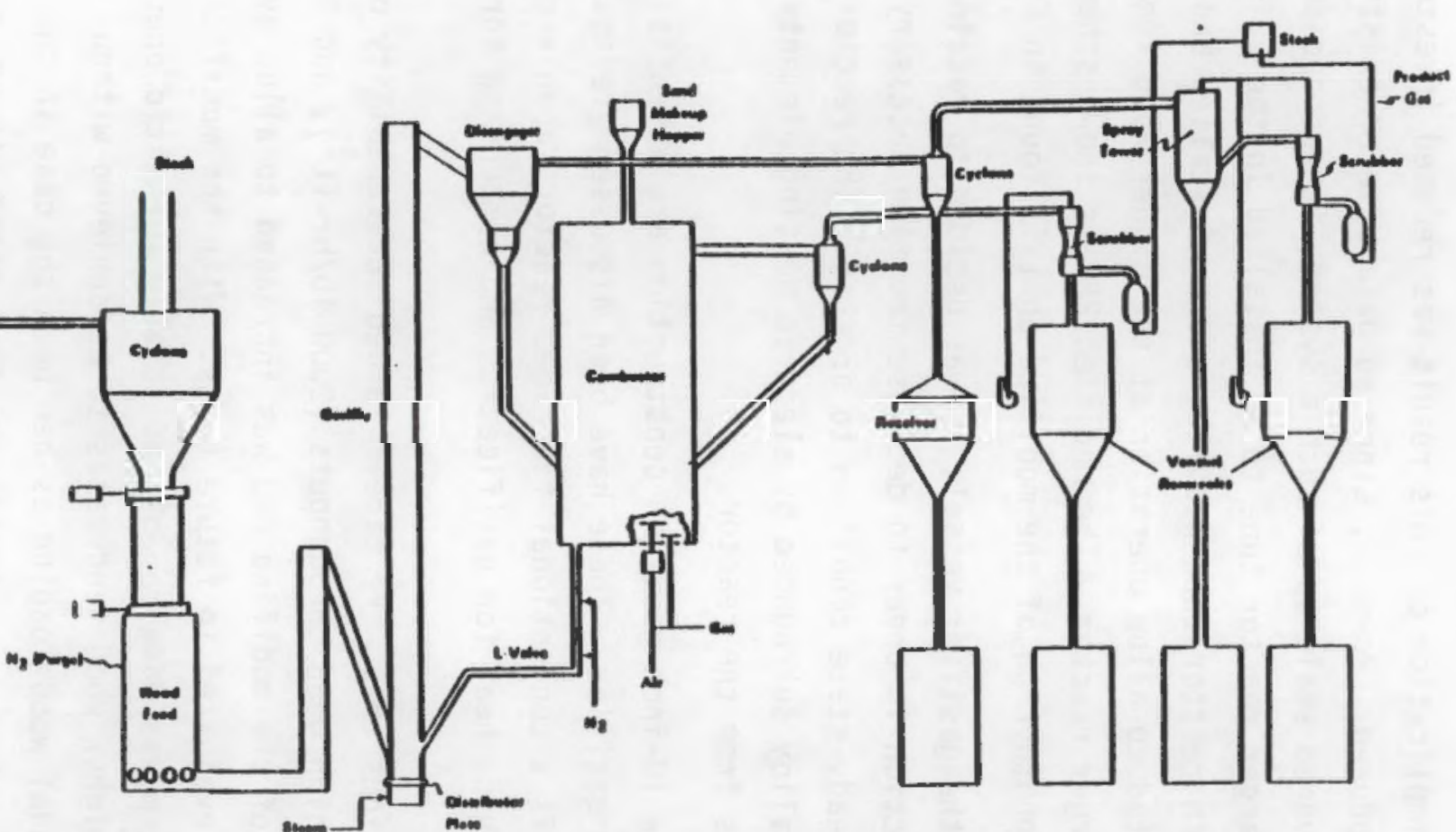

FIGURE 2. BATTELLE'S BIOMASS GASIFICATION PRU 
The wood and air are then transported into the PRU where the wood is separated from the conveying gas by a cyclone mounted on top of the wood lock-hopper system.

The wood feed system can be seen in Figure 3. A schematic of the feed system from the cyclone on is found in Figure 4. The feeder itseif separates the pressurizing, metering, and conveying functions to provide better control over the wood feeding. The wood metering bin is a live bottom bin containing 4-4-inch screws; these then empty into the two conveying screws that are 8 inches in diameter. The wood then falls into the base of the gasifier where it is contacted by the hot sand and steam.

Sequencing of the lock hoppers to re-load the metering bin is accomplished by a small micro-processor located in the control room. Sequence times as low as 2 to 3 minutes have been successfully achieved resulting in feed rates of about $2000 \mathrm{lb} / \mathrm{hr}$.

In order to successfully feed any material pneumatically, elutriation of fines must be kept to a minimum. Thus far, operation of the wood feed system has shown that elutriation of wood fines from the cyclone has not been a problem. Both wood chips and sawdust with a range of moisture leveis (5-50 percent) have successfully been fed through the pneumatic conveying system with no significant elutriation of fines from the system.

During previous phases of the test program, the feeder itself (excluding the pneumatic conveying) was shown to smoothly handle such diverse biomass forms as shredded bark, wood chips, and sawdust. These feed materials are shown in Figure 5 .

The first series of tests with the larger gasifier showed that a factor limiting wood throughput to the gasifier was heat transfer from the combustor. This shortcoming was traced to three major areas. These were the combustor refractory lining, sand loss from the combustor, ani Lvalve (solids transfer) capacity.

Inspection of the refractory lining in the combustor showed significant deterioration of the refractory's ability to insulate the vessel. The refractory lining was, therefore, replaced resulting in a significant improvement in combustor performance. 


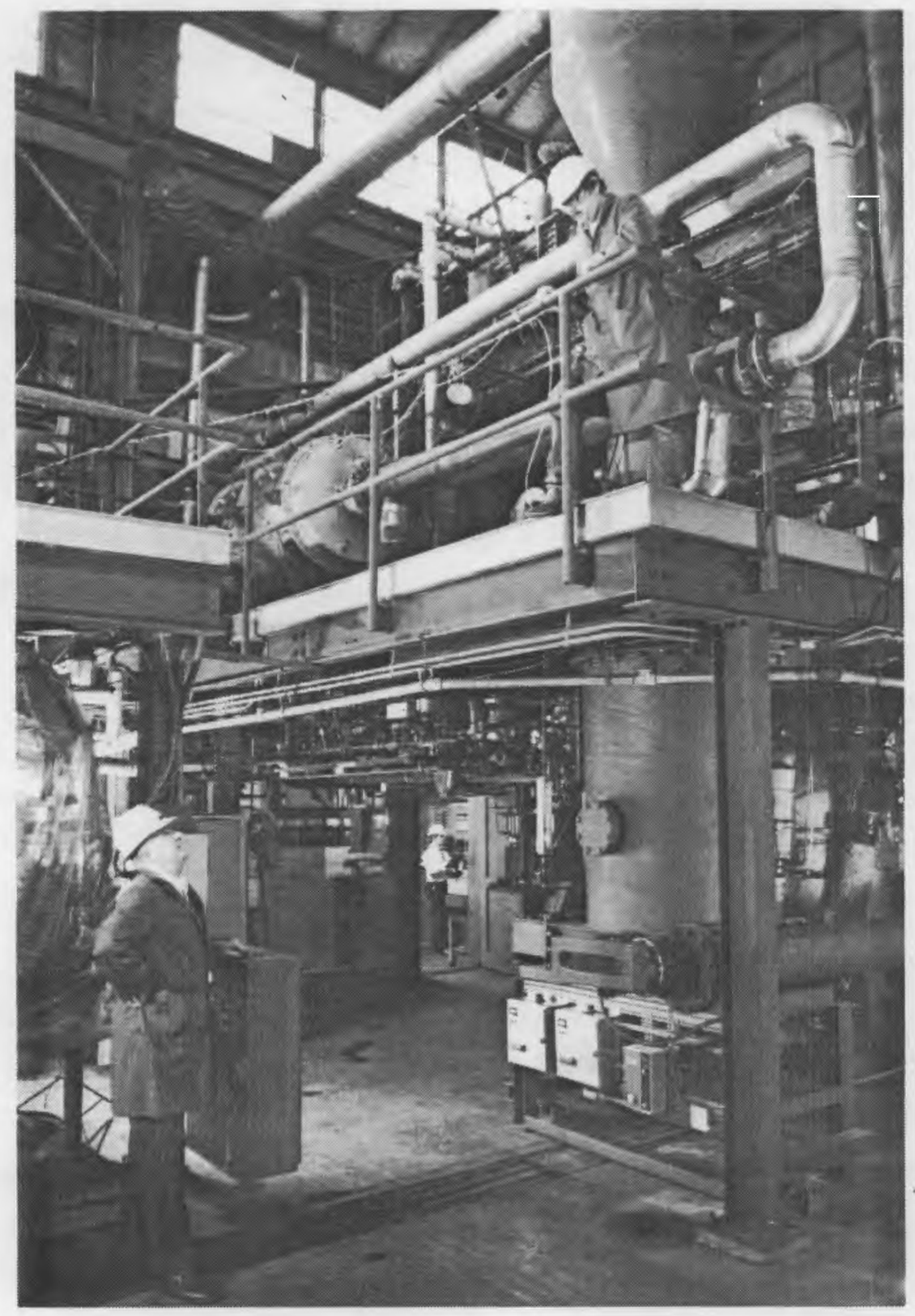

FIGURE 3. PHOTO OF BATTELLE'S BIOMASS GASIFICATION PRU 


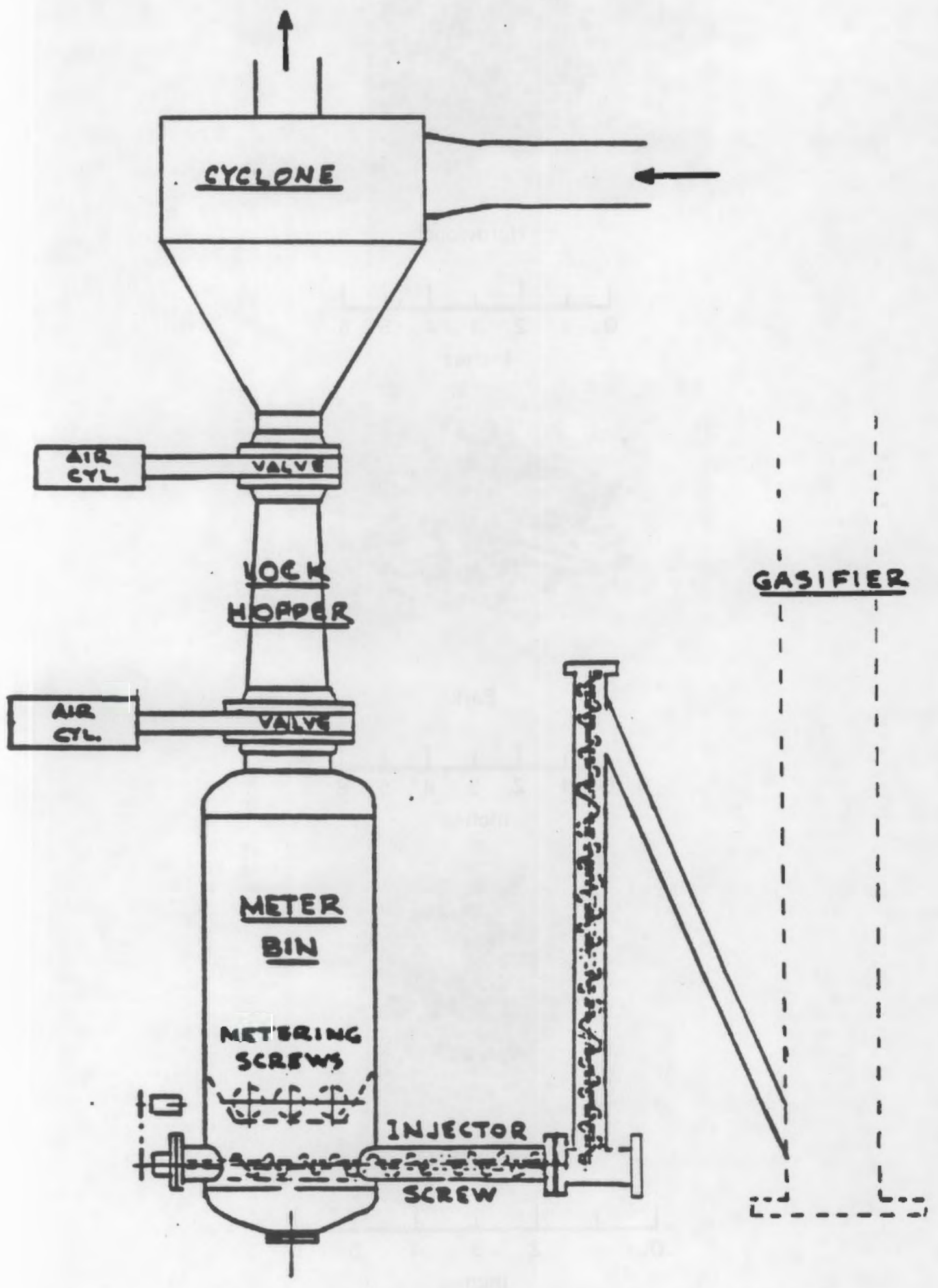

FIGURE 4. SCHEMATIC OF FEED SYSTEM(5) 


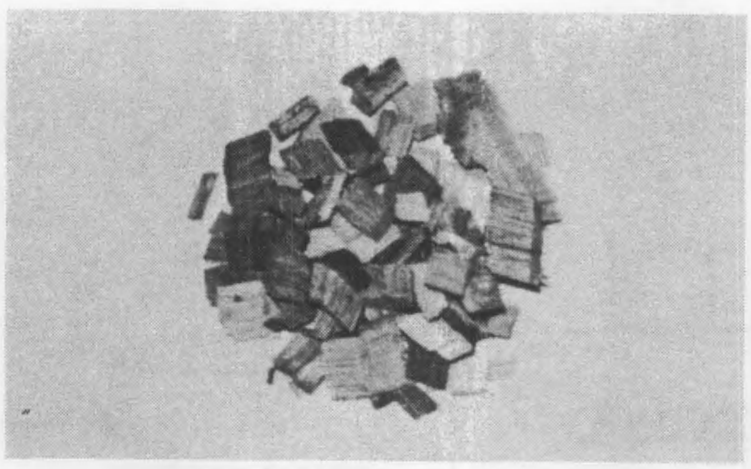

Hardwood
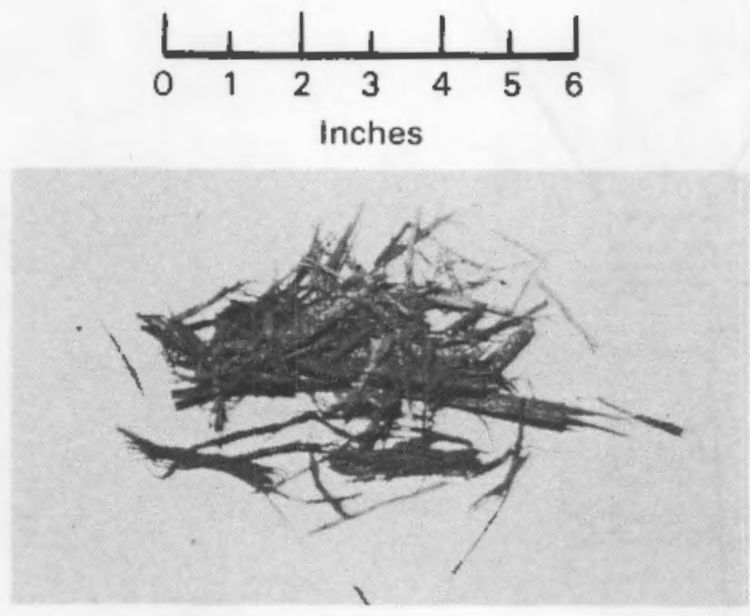

Bark
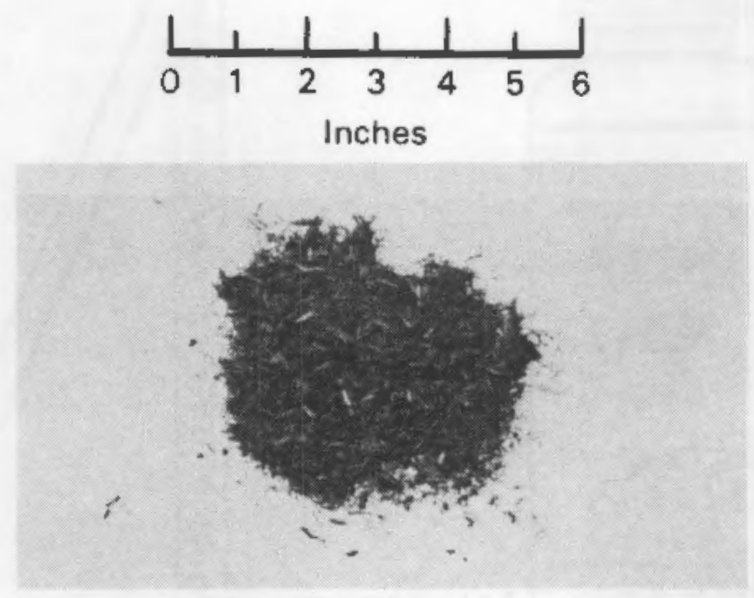

Sawdust

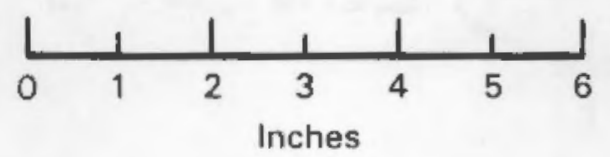

FIGURE 5. FORMS OF FEED MATERIALS 
While the refractory lining was being replaced, it became possible to install a sand return leg from the combustor cyclone so that elutriated sand could be returned to the combustor bed without additional handling. Sand makeup to the combustor bed had previously been a significant heat loss.

In order to provide more sand conveying capacity (and thus, more heat to the gasifier), the PRU-L-valve piping was enlarged from 3 inches to 4 inches. The L-valve is a non-mechanical valve which makes possible the regulation of hot sand flow from the combustor to the gasifier.

\section{EXPERIMENTAL RESULTS}

Biomass materials have inherently high reactivities when compared to more conventional fuels such as coal. As a result, a reactor utilizing biomass can achieve high carbon conversions at high throughputs at significantly lower temperatures than would be the case with coal. It is, therefore, possible to operate at much higher throughputs than are possible in conventional fluid bed reactors. A conventional fluid-bed reactor is limited to wood throughputs of about $200 \mathrm{lbs} / \mathrm{hr}^{-\mathrm{ft}^{2}}$. In the Battelle high throughput gasifier, however, the high reactivity of the wood feedstock is exploited so throughputs an order of magnitude higher than in conventional fluid-beds can be achieved. The result is a much smaller reactor resulting in significantly lower capital cost. Cost projections will be discussed in more detail below.

Initial tests in the 10-inch gasifier have been made in both the baseline (empty tube) and CTZ modes. A brief comparison of these results follows. Table 1 shows the data generated during the current phase of the program. Data designated as test $3 . X$ represents tests conducted prior to refractory replacement while those designated as test 4. $X$ are the tests made after the refractory replacement.

Table 2 shows the locations within the PRU where the data is collected. 
TABLE 1. DATA GENERATED DURING CURRENT PROGRAM PHASE

FOREST RESIDUE GASIFICATION RUN DATA (3RD PHASE-10"PRU)

\begin{tabular}{|c|c|c|c|c|c|c|c|}
\hline 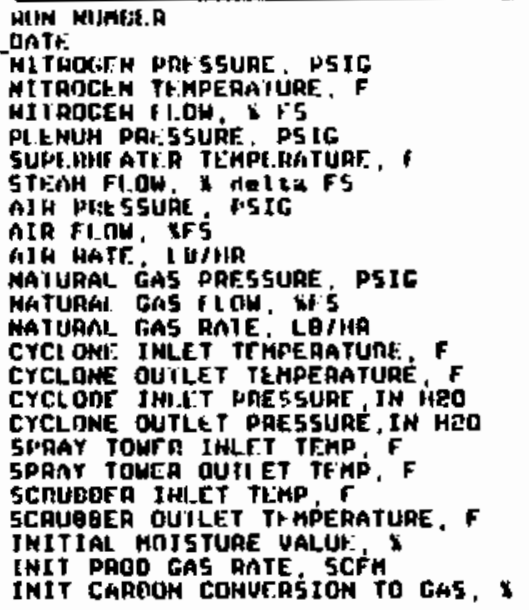 & 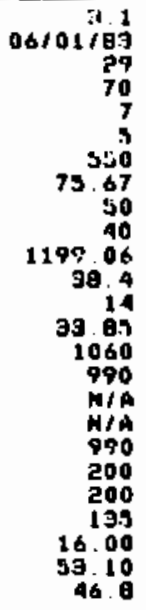 & $\begin{array}{r}3.4 \\
06 / 23 / 63 \\
25 \\
76 \\
12 \\
10 \\
270 \\
30.94 \\
57 \\
39 \\
1199.15 \\
37.2 \\
94 \\
32.16 \\
1976 \\
1264 \\
176 \\
163 \\
1764 \\
202 \\
202\end{array}$ & $\begin{array}{r}95 \\
06 / 20 / 83 \\
25 \\
80 \\
40 \\
11.6 \\
500 \\
4935 \\
59.9 \\
40 \\
1279.01 \\
36.6 \\
92 \\
50.31 \\
1432 \\
1326 \\
293 \\
218 \\
1326 \\
224 \\
224 \\
6.5 \\
900 \\
151.40 \\
79.4\end{array}$ & $\begin{array}{r}3.64 \\
06 / 30 / 43 \\
27 \\
61 \\
11 \\
119 \\
575 \\
61.24 \\
59.4 \\
40 \\
1299.26 \\
35.7 \\
47 \\
6043 \\
1329 \\
1297 \\
304 \\
217 \\
1237 \\
236 \\
296 \\
65 \\
9.00 \\
119.00 \\
51.3\end{array}$ & $\begin{array}{r}1251.1 \\
95 \\
65.1 \\
134 \\
125 \\
27 \\
20 \\
125 \\
20 \\
20 \\
6 \\
97 \\
127.7 \\
63 .\end{array}$ & $\begin{array}{r}36 \\
07+13 / 83 \\
27 \\
97 \\
10 \\
966 \\
570 \\
5152 \\
59.4 \\
40 \\
1283.22 \\
96.6 \\
56 \\
67.73 \\
1303 \\
1212 \\
171 \\
157 \\
1212 \\
202 \\
202 \\
66\end{array}$ & $\begin{array}{r}9 \\
55 \\
512 \\
39 \\
03 \\
13 \\
12\end{array}$ \\
\hline
\end{tabular}

FOREST RESIDUE GASIFICATION RUN RESULTS

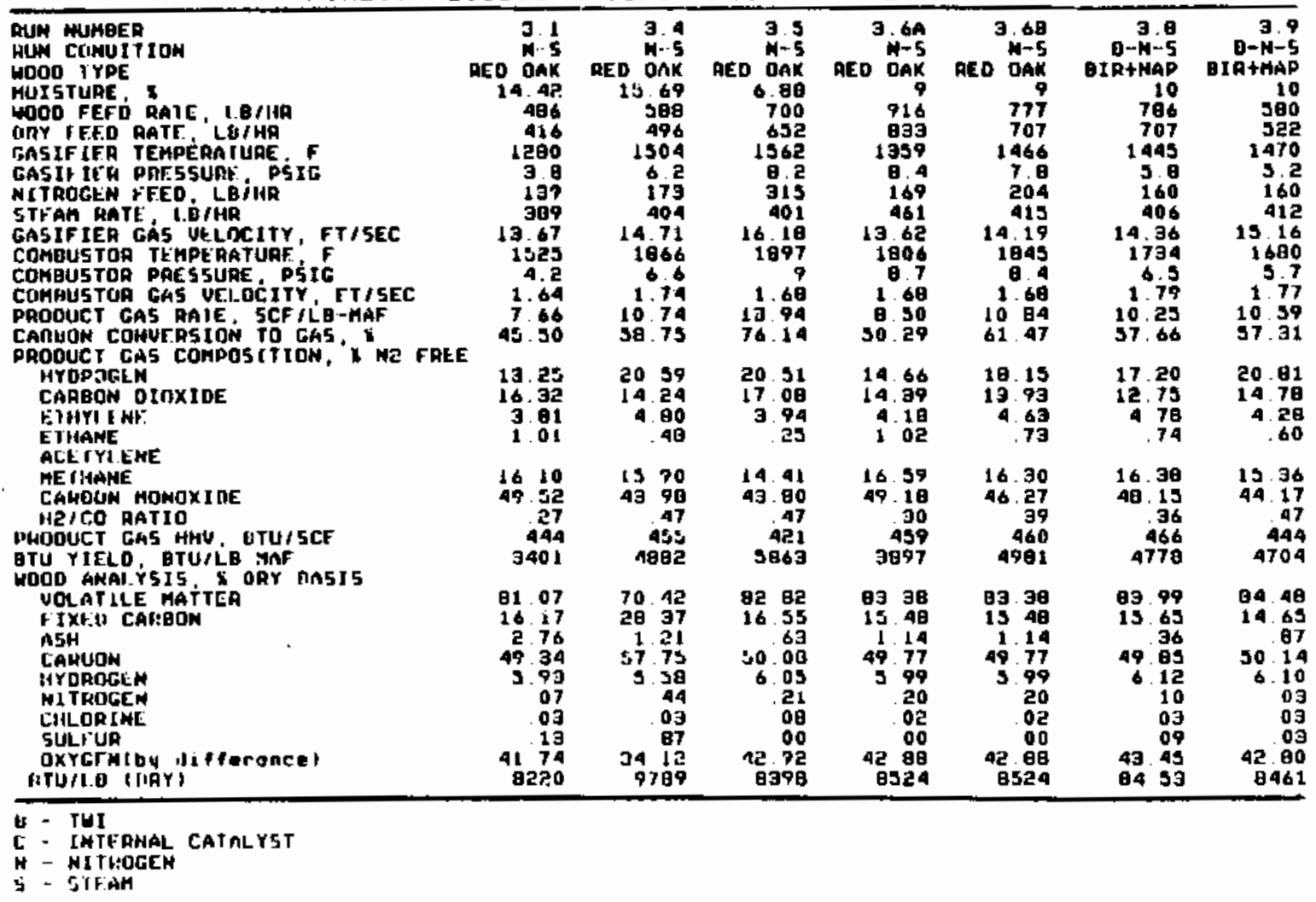


TABLE 1. (continued)

FOREST RESIDUE GASIFICATION RUN DATA (3RD PHASE-10"PRU)

\begin{tabular}{|c|c|c|c|c|c|c|c|c|}
\hline 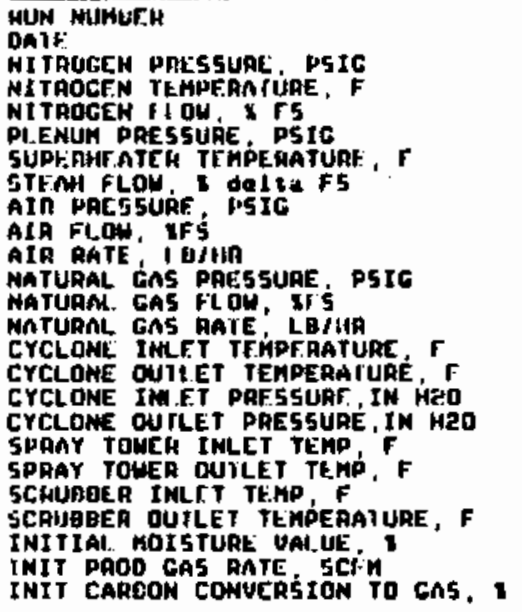 & $\begin{array}{r}08117 \\
3915 \\
59 \\
39\end{array}$ & 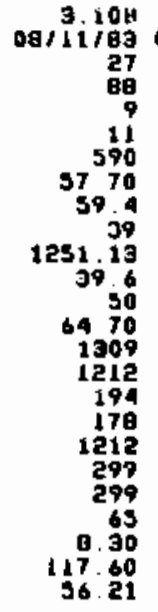 & 09107 & $\begin{array}{r}4 \\
67 \\
5829 \\
40\end{array}$ & $\begin{array}{r}9 \\
65 \\
48\end{array}$ & $\begin{array}{r}11 \\
30\end{array}$ & 1 & 6 \\
\hline
\end{tabular}

FOREST RESIDUE GASIFICATION RUN RESULTS

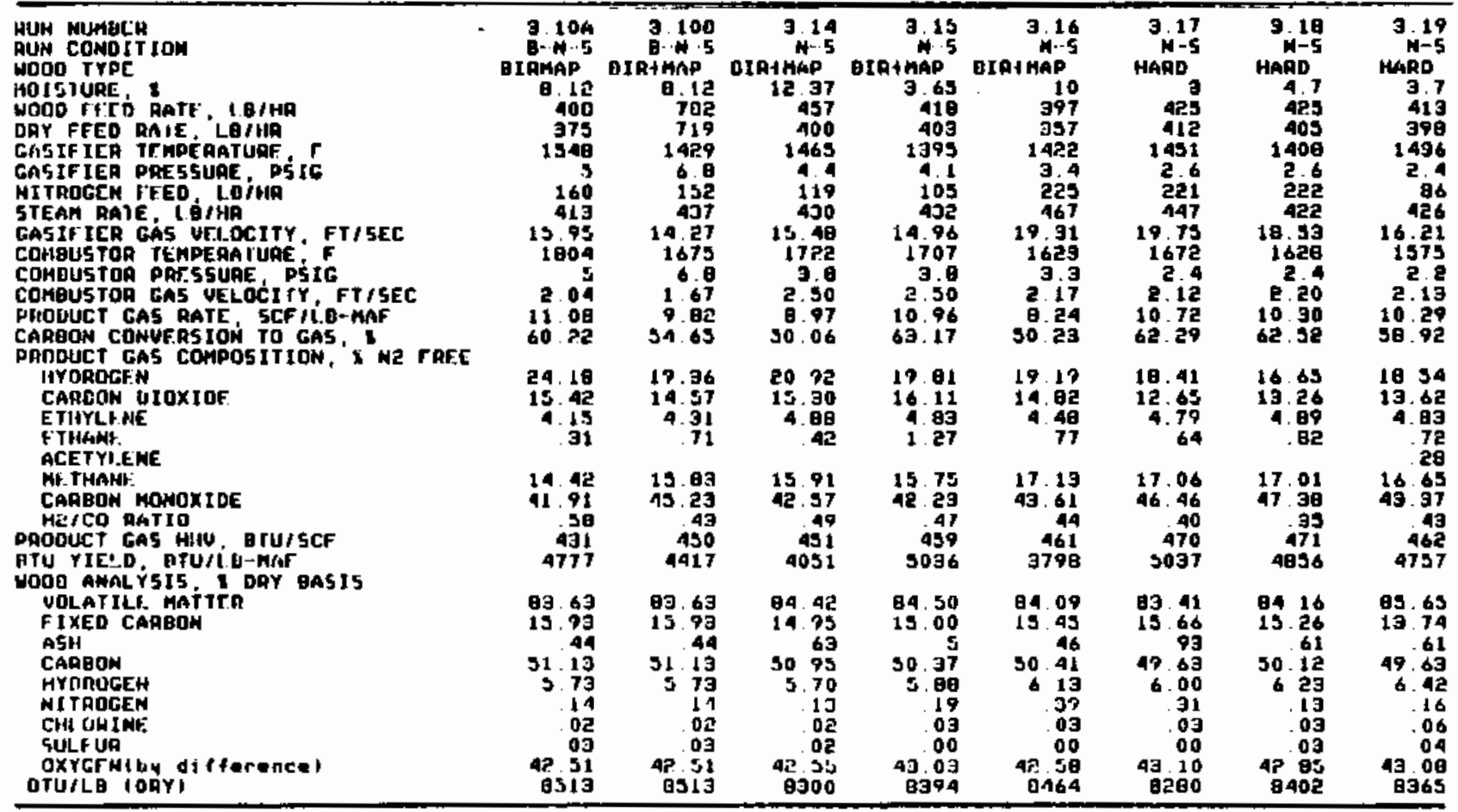

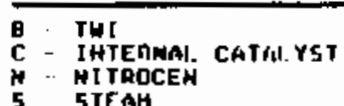


TABLE 1. (continued)

FOREST RESIDUE GASIFICATION RUN DATA

\begin{tabular}{|c|c|c|c|c|c|c|c|c|}
\hline 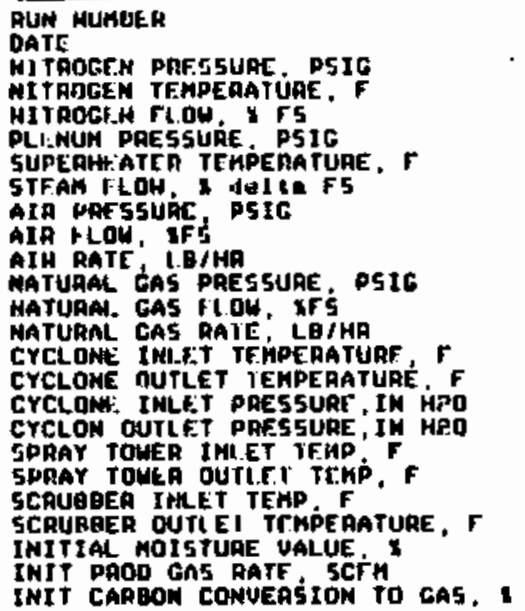 & $\begin{array}{r}3.20 \\
11102 / 93 \\
25 \\
60 \\
4 \\
6 \\
620 \\
66.64 \\
48 \\
48 \\
1416.46 \\
35.7 \\
90 \\
49.28 \\
1814 \\
1102 \\
99 \\
74 \\
1102 \\
119 \\
119 \\
50 \\
13.00 \\
50.34 \\
59.68\end{array}$ & $\begin{array}{r}921 \\
11108 / 83 \\
25 \\
61 \\
6 \\
8 \\
630 \\
62.11 \\
48 \\
78 \\
1416.46 \\
96 \\
48 \\
61.25 \\
1283 \\
1174 \\
106 \\
67 \\
1174 \\
119 \\
119 \\
58 \\
4.30 \\
66.43 \\
56.15\end{array}$ & $\begin{array}{r}3.22 A \\
1110 / 83 \\
25 \\
58 \\
6 \\
8.4 \\
625 \\
63.63 \\
49.2 \\
50 \\
1409.54 \\
94.2 \\
30 \\
53.52 \\
1190 \\
1150 \\
104 \\
95 \\
1150 \\
41 A \\
119 \\
57 \\
10.00 \\
41.18 \\
57.45\end{array}$ & $\begin{array}{r}3.270 \\
1110 / 83 \\
25 \\
20 \\
5.5 \\
0.9 \\
635 \\
64.70 \\
49.2 \\
51 \\
1519.33 \\
94.9 \\
39 \\
53.65 \\
1214 \\
1174 \\
118 \\
106 \\
1174 \\
114 \\
414 \\
10.00 \\
40.23 \\
55.69\end{array}$ & $\begin{array}{r}3.23 \\
11 / 16 / 83 \\
25 \\
j 0 \\
6 \\
7.6 \\
600 \\
65.00 \\
40 \\
30 \\
005.29 \\
39.6 \\
39 \\
53.69 \\
1100 \\
M / A \\
K / A \\
H / A \\
N / A \\
H / A \\
W / A \\
60 \\
33.00 \\
30.00 \\
41.68\end{array}$ & $\begin{array}{r}3.24 \\
1 / 10 / 93 \\
25 \\
70 \\
1.5 \\
7.2 \\
660 \\
65.49 \\
49.6 \\
23 \\
681.96 \\
42.6 \\
50 \\
66.46 \\
1171 \\
150 \\
108 \\
112 \\
158 \\
1 / 4 \\
1 / 4 \\
56 \\
49.00 \\
35.40 \\
48.18\end{array}$ & $\begin{array}{r}3.25 A \\
12 / 13 / 63 \\
25 \\
46 \\
3 \\
9.6 \\
630 \\
55.97 \\
49 \\
39 \\
1150.89 \\
49.2 \\
30 \\
66.81 \\
1958 \\
1131 \\
157 \\
138 \\
1131 \\
N / A \\
N / 9\end{array}$ & $\begin{array}{r}10 \\
6 \\
42 . \\
47 \\
1350 \\
42 \\
61 . \\
12 \\
10 \\
9 \\
10 \\
4 \\
149 \\
59 \\
55\end{array}$ \\
\hline
\end{tabular}

FOREST RESIDUE GASIFICATION RUN RESULTS

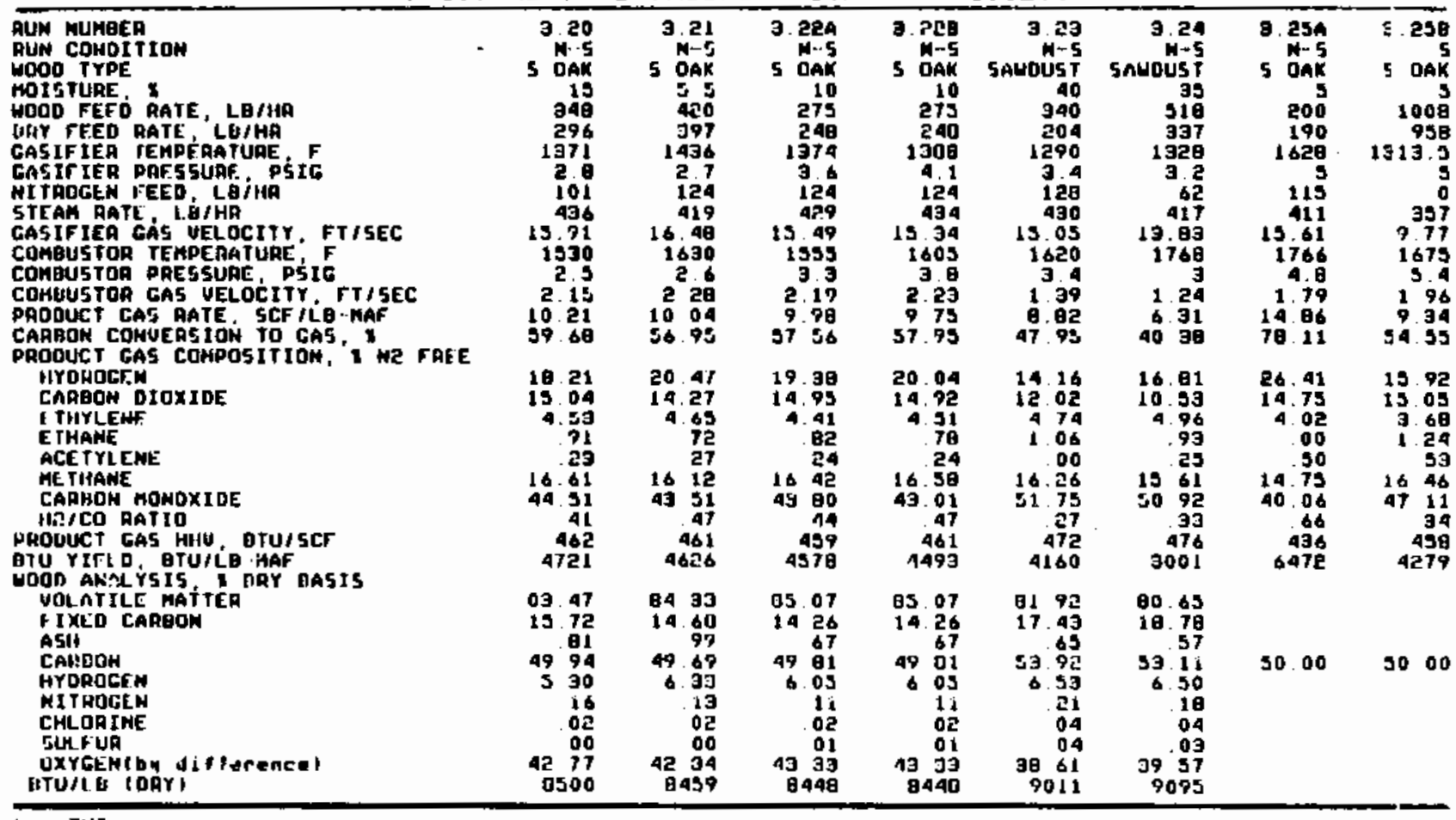

C : IHI INTEMAL CATALYST

h. HITAOCTh

5. 5TEAH 
TABLE 1. (continued)

FOREST RESIDIJE GASIFICATION - DATA SUMMARY (4TH PHASE)

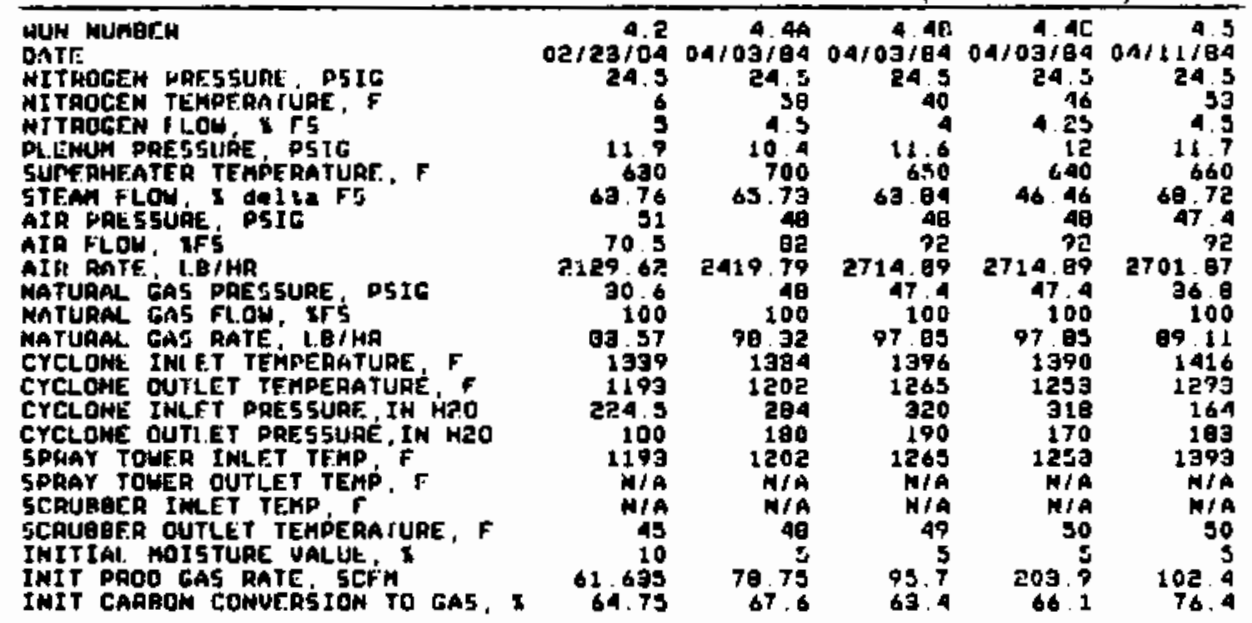

FOREST RESIDUE GASIFICATION RUN RESULTS

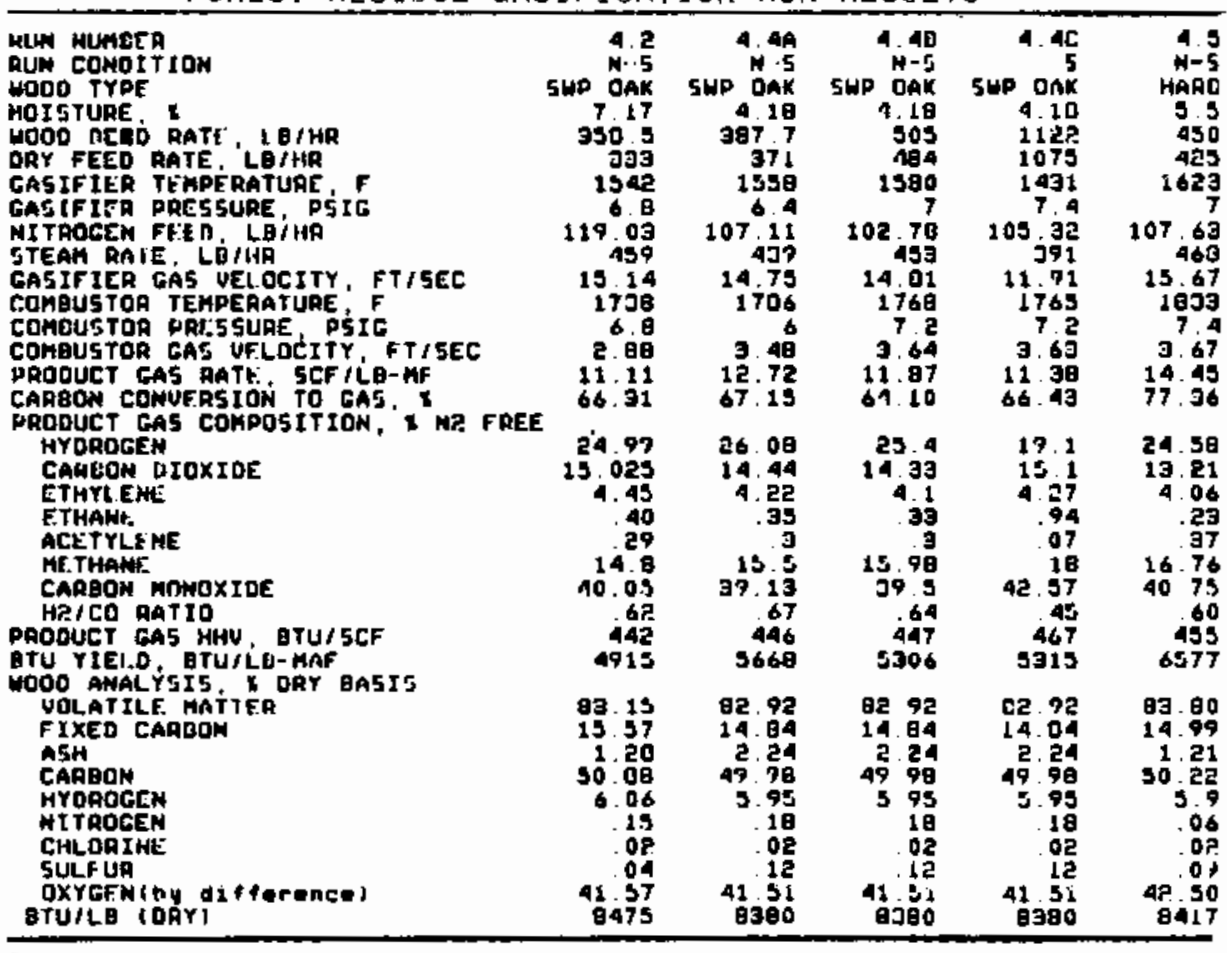

a - THT

c - InTFRMal ChTALYST

5 - MITROGEM 
TABLE 2. DATA SOURCES

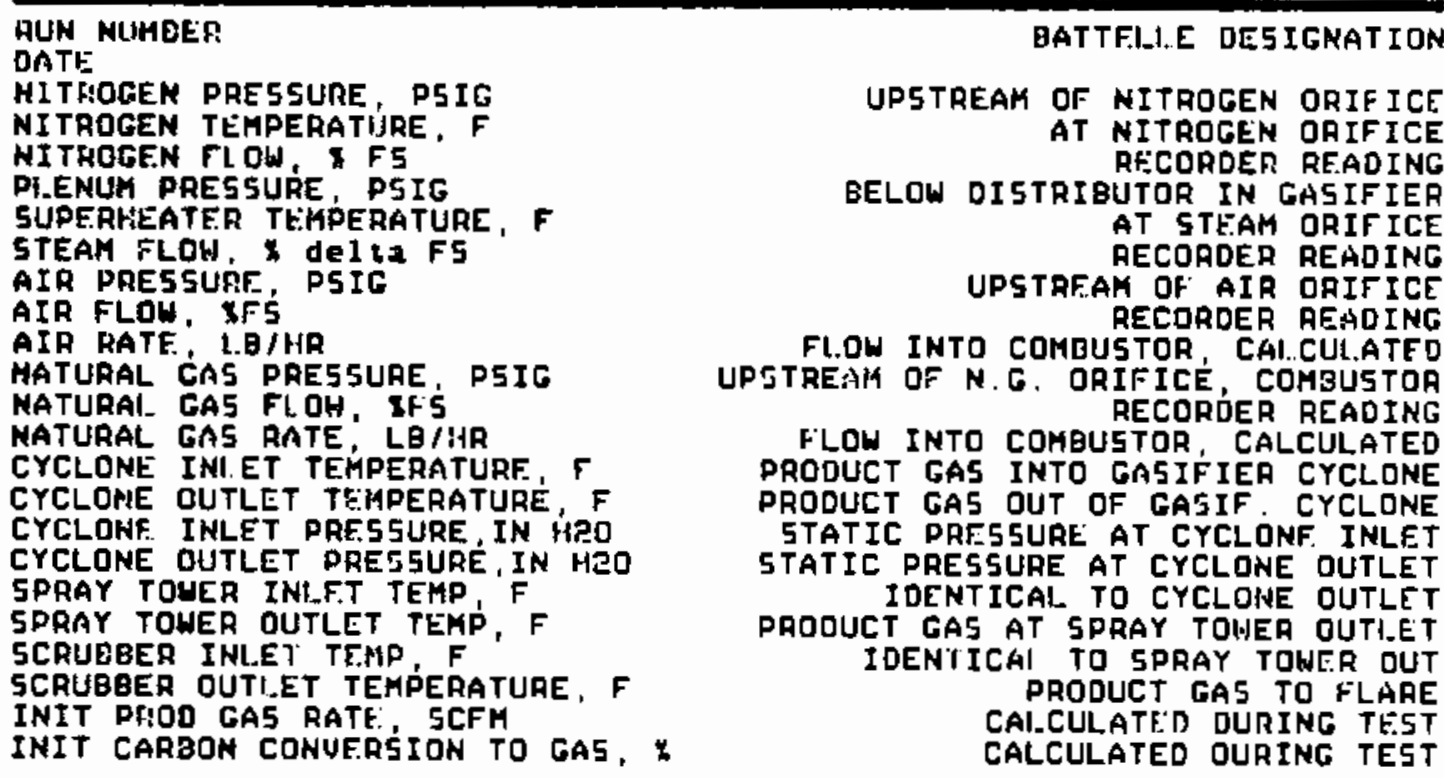

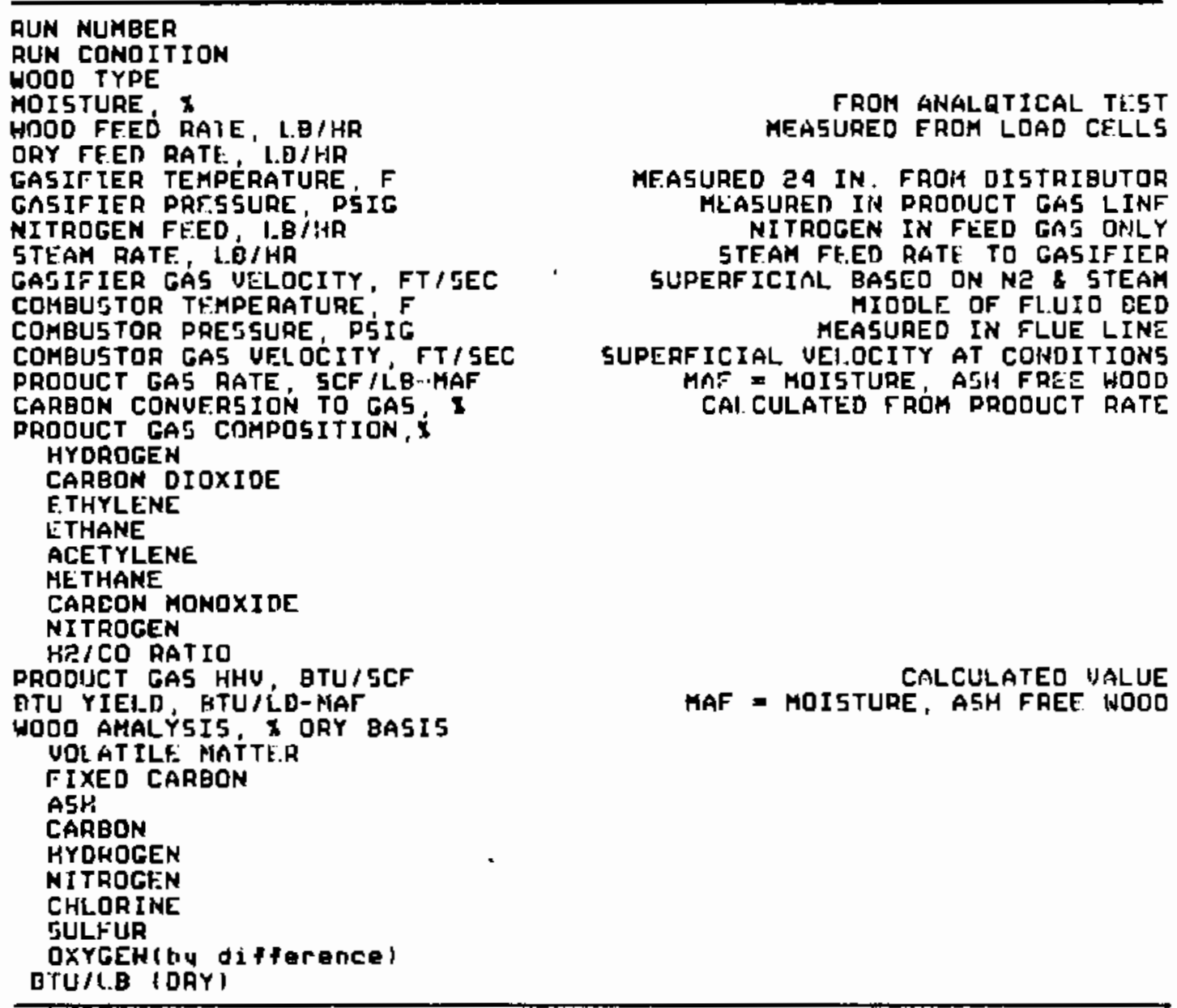


Baseline Mode Tests

"Baseline" tests, thus far, in the 10-inch gasifier have shown that wood conversion levels are significantly improved over those achieved in the 6 -inch unit. Figure 6 shows the results of these tests compared to the baseline conversion curve generated during earlier phases of the program. The improvement in conversion levels noticed in the 10-inch unit is most likely due to improved contacting between the wood and the hot sand at the base of the gasifier. The gasifier has been operated in the

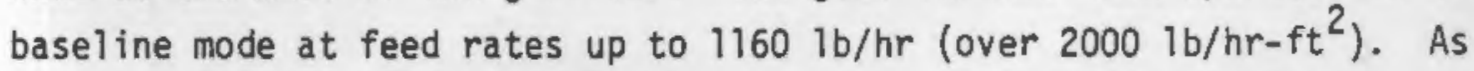
can be seen, the combustor modifications that were made have made possible the achievement of temperatures in excess of $1600 \mathrm{~F}$ in the gasifier at throughputs up to approximately $10001 \mathrm{~b} / \mathrm{hr}-\mathrm{ft}^{2}$. However, experience thus far indicates that throughputs will still be limited by the ability to maintain gasifier temperatures with the limiting factor being the maximum heat generation rate of the combustor.

Therefore, in a commercial plant, with its inherently lower heat losses, considerably higher throughtpus may be achieved. In subsequent phases. of the gasification program, we will try to determine the factors that are likely to ultimately limit the throughput in this type of gasifier. Further tests will then be made to evaluate the maximum throughputs attainable in the baseline mode.

Tests in the Modified Gasifier

As mentioned above, during the previous phase of the program, the use of proprietary internals resulted in significant increases in carbon conversion. The TWI's produce zones of highly backmixed solids resulting in increased contacting between wood particles and hot sand. Initial experiments in the TWI mode with the 6-inch reactor showed that carbon conversion levels up to 90 percent could be achieved with no reduction in total reactor throughput. These results have been discussed in a previous publication. (2)

With the TWI's in place in the 10-inch unit, carbon conversions slightly lower than had been achieved earlier in the 6-inch unit as can be seen in Figure 7 . However, as Figure 6 indicates, carbon conversions 


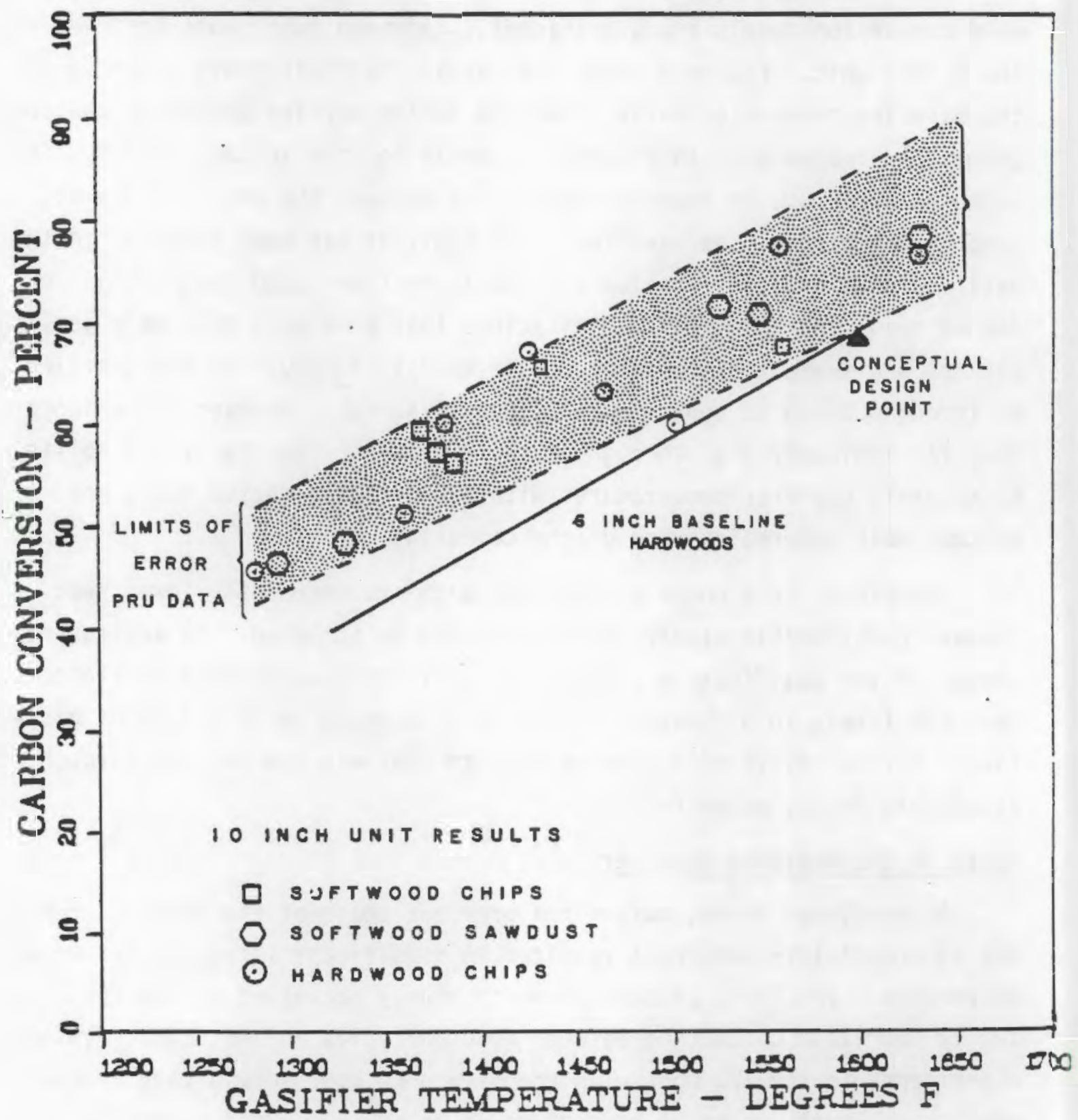

FIGURE 6. BATTELLE'S BIOMASS GASIFICATION (10 inch unit results compared to 6 inch unit results) 


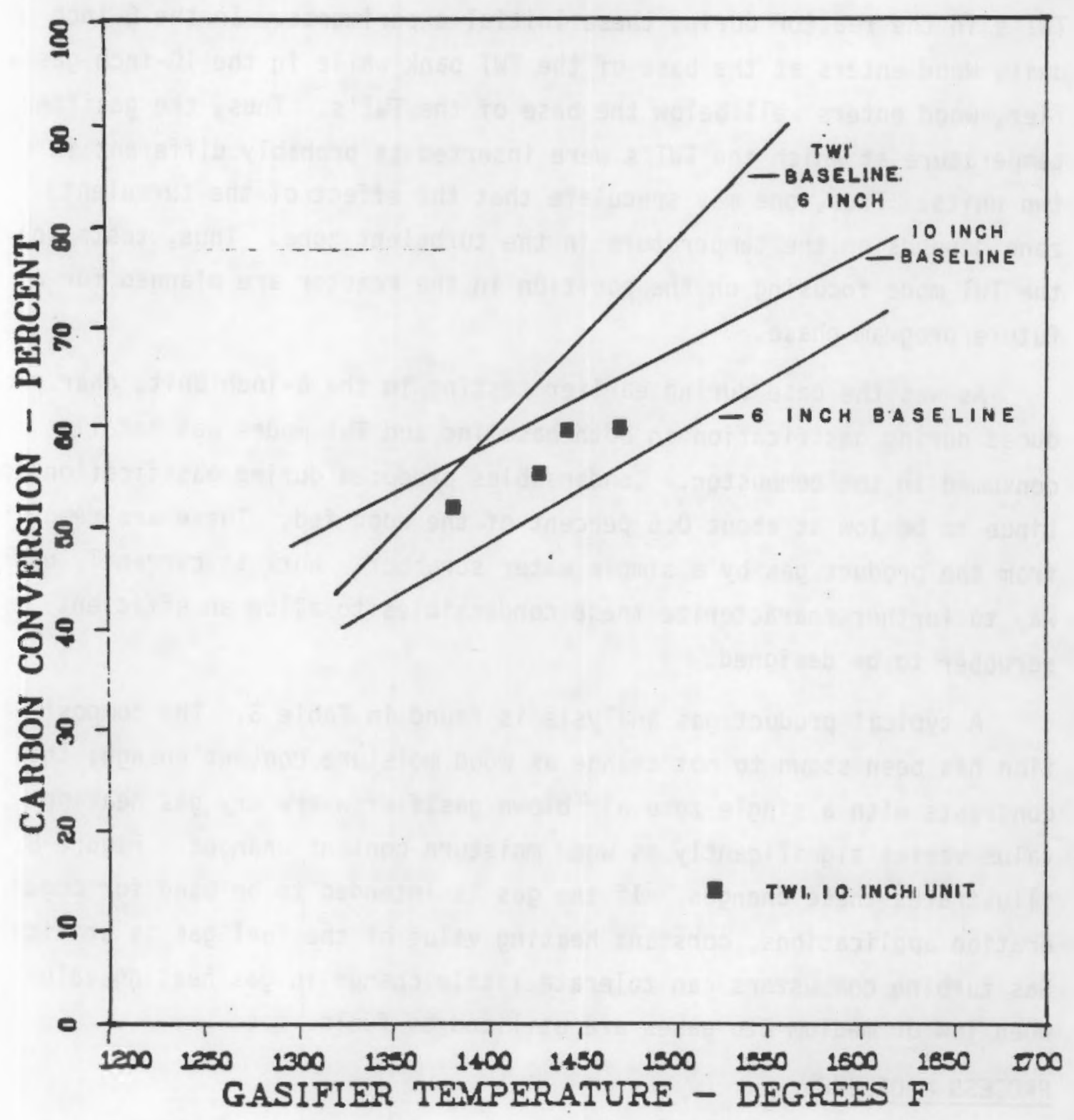

FIGURE 7. BATTELLE'S BIOMASS GASIFICATION

(TWI results 10 inch gasifier) 
with the empty 10-inch tube were significantly above those in the empty 6-inch tube. The fact that the TWI's did not further increase carbon conversion in the 10-inch unit could be due to the physical position of the TWI's in the reactor during these initial experiments. In the 6-inch unit, wood enters at the base of the TWI bank while in the 10-inch gasifier, wood enters well below the base of the TWI's. Thus, the gasifier temperature at which the TWI's were inserted is probably different in the two units. Thus, one may speculate that the effect of the turbulent zone depends on the temperature in the turbulent zone. Thus, tests in the TWI mode focusing on the position in the reactor are planned for a future program phase.

As was the case during earlier testing in the 6-inch unit, char produced during gasification in both baseline and TWI modes was totally consumed in the combustor. Condensibles produced during gasification continue to be low at about 0.5 percent of the wood fed. These are removed from the product gas by a simple water scrubber. Work is currently under way to further characterize these condensibles to allow an efficient scrubber to be designed.

A typical product gas analysis is found in Table 3 . The composition has been shown to not change as wood moisture content change; this contrasts with a single zone air blown gasifier where dry gas heating value varies significantly as wood moisture content changes. Figure 8 illustrates these changes. If the gas is intended to be used for cogeneration applications, constant heating value of the fuel gas is critical. Gas turbine combustors can tolerate little change in gas heating value when low or medium Btu gases are utilized as fuels.

\section{PROCESS MODELING}

A computer model has been constructed to simulate performance of a commercial Forest Residue Gasification (FRG) system. This consists of a complete mass and energy balance that takes into account heat losses. Heat losses have been accurately calculated for each major process vessel as well as process piping, allowing a realistic system simulation. Flexibility is built in to allow for exploring the effect of operating 
TABLE 3. TYPICAL PRODUCT GAS ANALYSIS

\begin{tabular}{lc}
\hline & Volume, * Ory \\
\hline $\mathrm{H}_{2}$ & 16.0 \\
$\mathrm{CO}_{2}$ & 12.8 \\
$\mathrm{C}_{2} \mathrm{H}_{4}$ & 6.0 \\
$\mathrm{C}_{2} \mathrm{H}_{6}$ & 1.0 \\
$\mathrm{CH}_{4}$ & 16.5 \\
$\mathrm{CO}$ & 47.7 \\
\hline
\end{tabular}




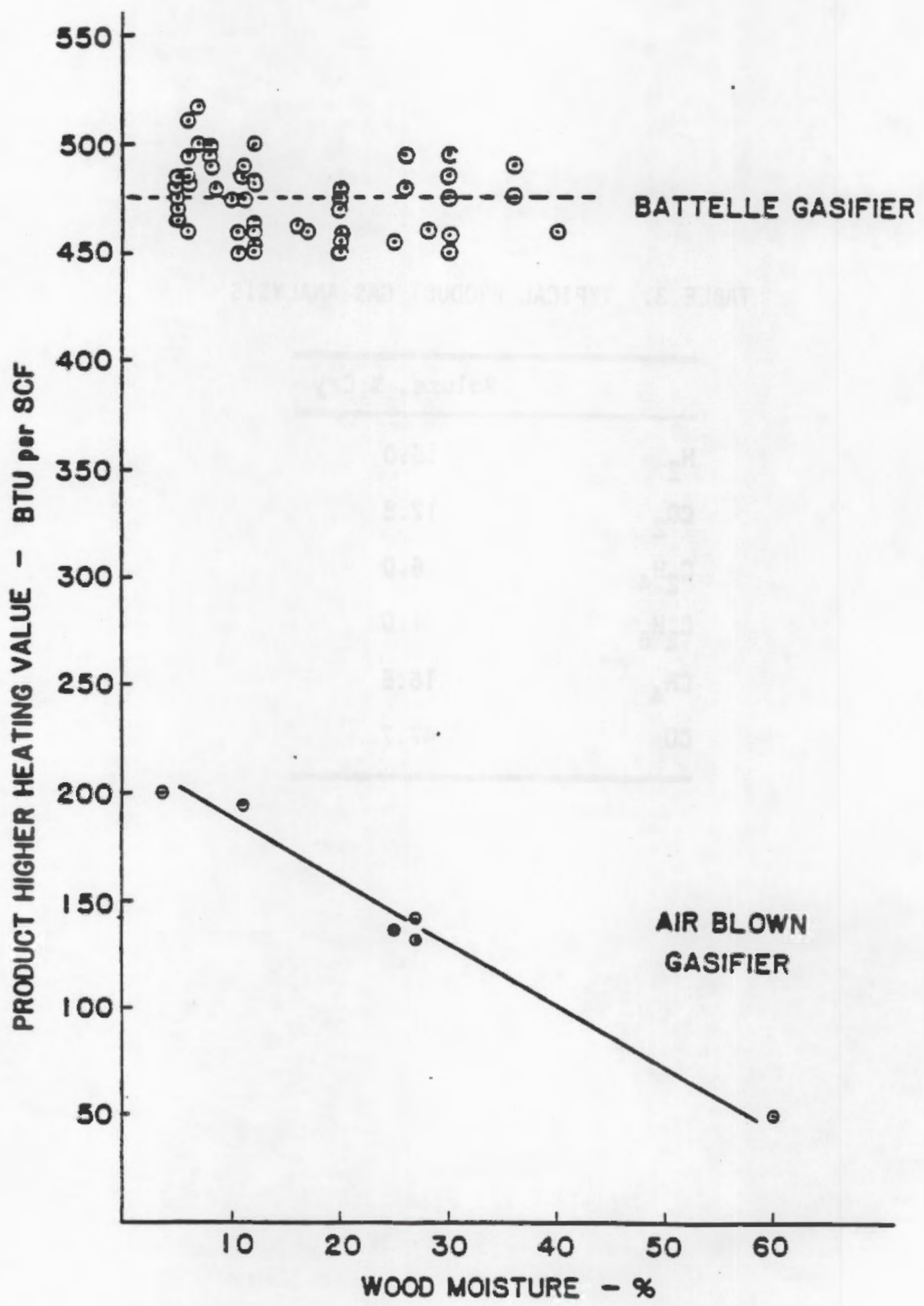

FIGURE 8. PRODUCT GAS HEATING VALUE VARIES SIGNIFICANTLY WITH FEED MOISTURE IN AN AIR BLOWN SYSTEM 
and design parameters on system performance and operation. In addition to helping with process conceptual designs, the model can be used to determine the most critical experimental parameters for future PRU tests as well as to interpret the resuits of these tests. The model allows the calculation of thermal performance in terms of controllable process and design parameters, as well as determining sensitivities and optimizations of process parameters such as temperatures and flow rates. Performance can be rapidly evaluated under a variety of conditions.

\section{Model Operation}

The model predicts performance as a function of tweive variables. These variables include:

- plant size

- wood type

- wood analysis

- wood heating value

- feed moisture

- gasifier temperature, or

- carbon conversion to gas

- gas composition

- carbon conversion to liquid products

- flue gas to steam efficiençy

- heat loss from plant

- turndown.

To accomplish these calculations, inputs of feedstock-type, plant size, and operating conditions are employed. The first step in the calculations is a mass balance over the system.

In calculating the mass balance, experimental data generated in the PRU is used to predict the elemental balance around the gasifier and generate numerical values for the gasifier exit streams such as the product gas, char, condensible organics, and circulating sand. In combination with the energy balance, the relative mass flows are balanced so that the char sent to the combustor is enough to satisfy heat loads with no excess char or heat production. PRU testing has shown that this calculated "balance point", in fact, can be achieved at the design temperatures and flow rates. 
With mass flows determined, the vessel sizes are calculated in a subroutine using experimental data on vessel throughputs and conventional design methods for other process vessels such as cyclones. These vessel sizes are then used as inputs for determining heat losses from the system.

In predicting "balanced operation", the model adjusts the mass balance so as to achieve thermally balanced operation. That is, each section of the plant is in thermal equilibrium, where heat inputs equal outputs (including heat loss) at steady state. This is accomplished using an iterative technique. An initial condition (gasifier temperature or carbon conversion) is chosen. It is then determined if the char is sufficient for the heat load on the combustor, from which the gasifier heat requirement is supplied. The gasifier and combustor temperatures are then adjusted so that the char produced is just enough to supply the system's heat requirements. Additionally, the drying of the wood is adjusted so that the flue gas dries the wood as close to 10 percent moisture as possible. Each time a new feed moisture is determined, a new balance between the gasifier and combustor is calculated.

However, if one is interested in a particular situation, all these iterations need not be used. A specific condition (e.g., carbon conversion or gasifier temperature) can be stated. The output can then be studied to determine the effect on. the net heat requirements, or excess heat production, in the combustor. In addition, if the specified inputs create a net heat requirement then the required amount of auxiliary combustion fuel to meet this requirement will be calculated. For example, if it were assurned higher carbon conversions in the gasifier were possible, a case could be run where the model will predict the additional heat requirement in the combustor due to lack of char, and the auxiliary wood required to supply this heat. This gives the capability to explore alternate options and how operation would be affected. A simplified flow diagram of the program is presented in Figure 9. 


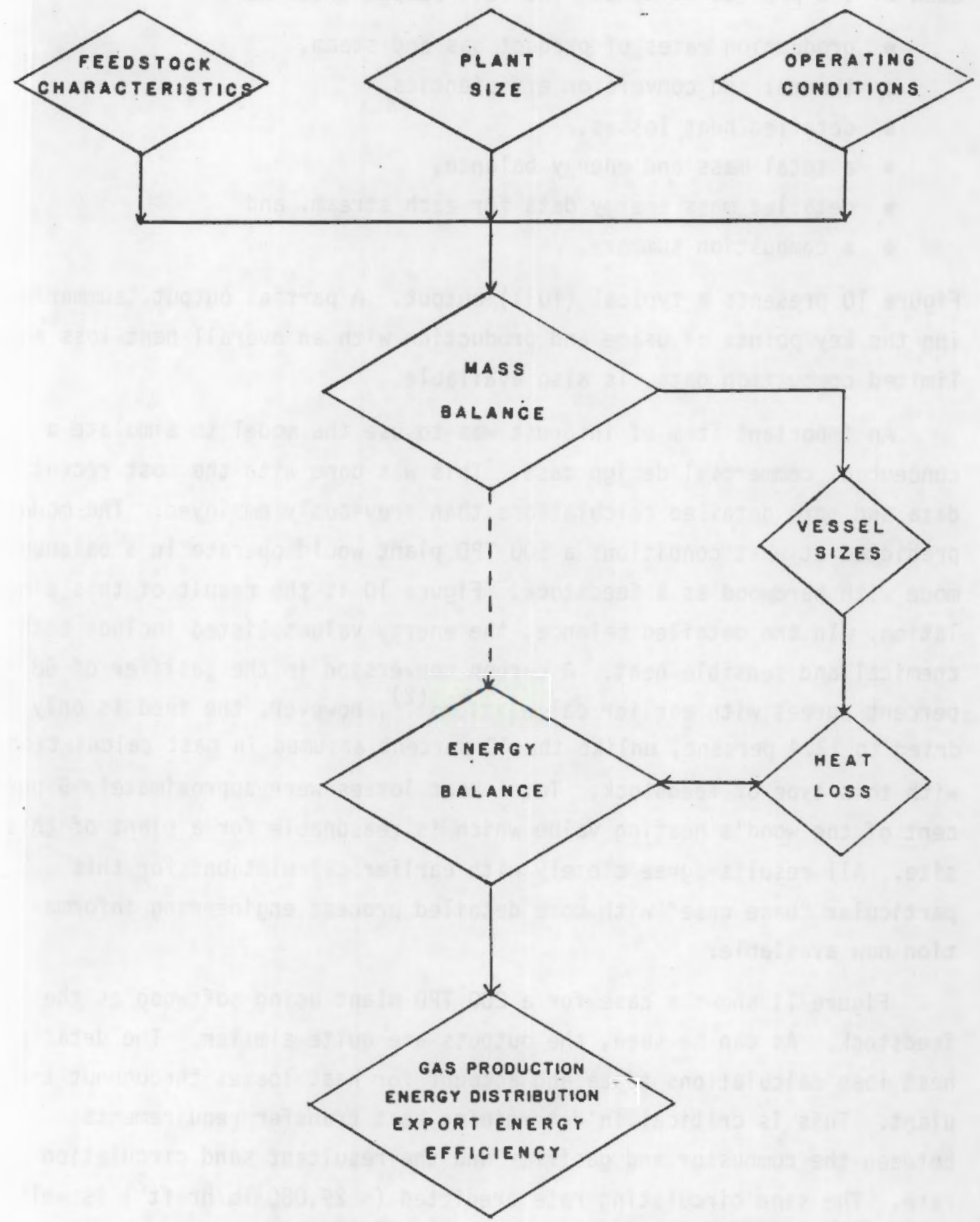

FIGURE 9. BATTELLE'S BIOMASS GASIFICATION COMPUTER MODEL 
The model output provides a process summary as well as details of each of the process streams. The full output includes:

- production rates of product gas and steam,

- thermal and conversion efficiencies,

- detailed heat losses,

- a total mass and energy balance,

- detailed mass energy data for each stream, and

- a combustion summary.

Figure 10 presents a typical (full) output. A partial output, summarizing the key points of usage and production with an overall heat loss and limited combustion data, is aiso available.

An important item of interest was to use the model to simulate a conceptual commercial design case. This was done with the most recent data and more detailed calculations than previously employed. The model predicted at what conditions a 500 TPO plant would operate in a balanced mode with hardwood as a feedstock. Figure 10 is the result of this simulation. In the detailed balance, the energy values listed include both chemical and sensible heat. A carbon conversion in the gasifier of 68 percent agrees with earlier calculations ${ }^{(2)}$, however, the feed is only dried to 12.4 percent, unlike the 10 percent assumed in past calculations with this type of feedstock. Total heat losses were approximately 5 percent of the wood's heating value which is reasonable for a plant of this size. All results agree closely with earlier calculations for this particular "base case" with more detailed process engineering information now available.

Figure 11 shows a case for a 200 TPD plant using softwood as the feedstock. As can be seen, the outputs are quite similar. The detailed heat loss calculations trace and account for heat losses throughout the plant. This is critical in determining heat transfer requirements between the combustor and gasifier and the resultant sand circulation rate. The sand circulating rate predicted $\left(\sim 29,0001 \mathrm{~b} / \mathrm{hr}^{-f t^{2}}\right)$ is well within experimentally determined transfer capabilities of the L-valve. Earlier heat loss estimates were more conservative and not as representative of the true performance of the system. However, since heat losses 


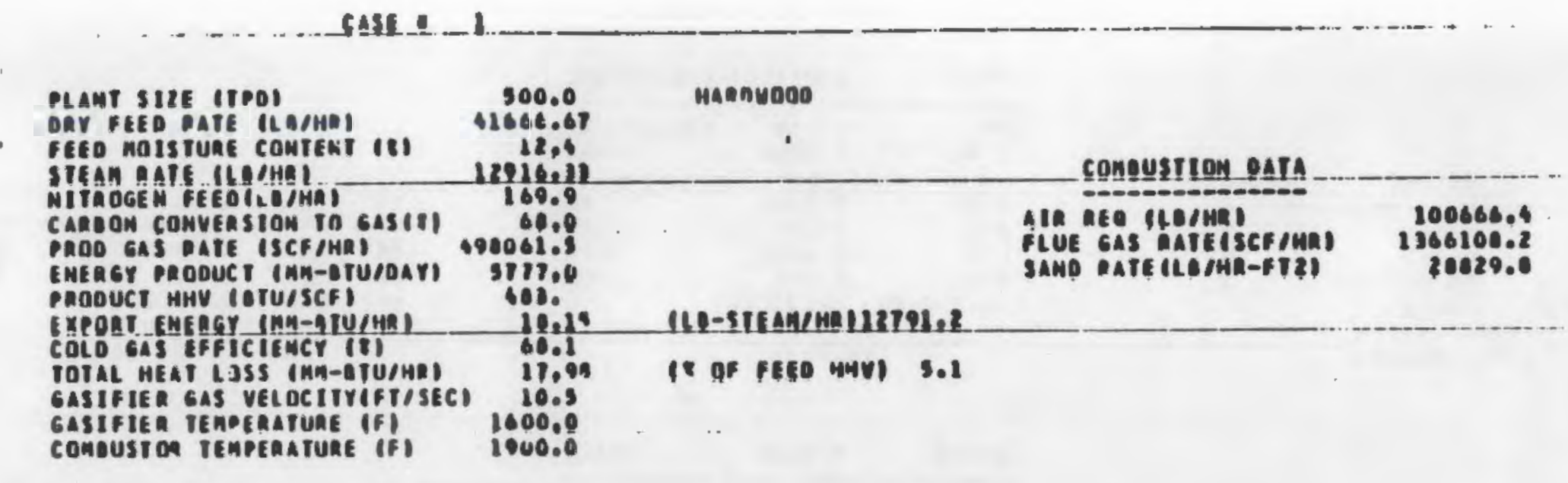

VESSEL SIIES (FT)
GesgIEIER

FIGURE 10. MASS ANO ENERGY BALANCE SUMMARY FOR FOREST RESIOUE GASIFICATION MODEL 


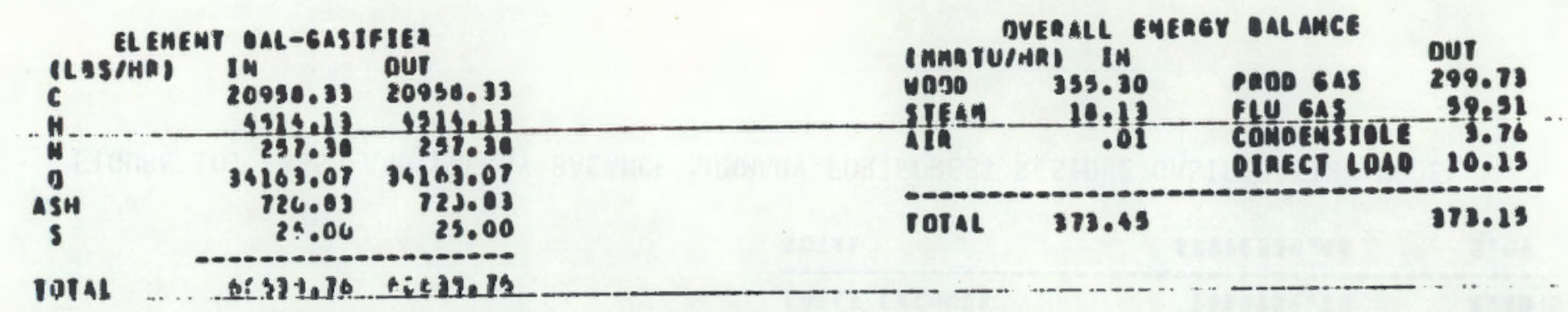

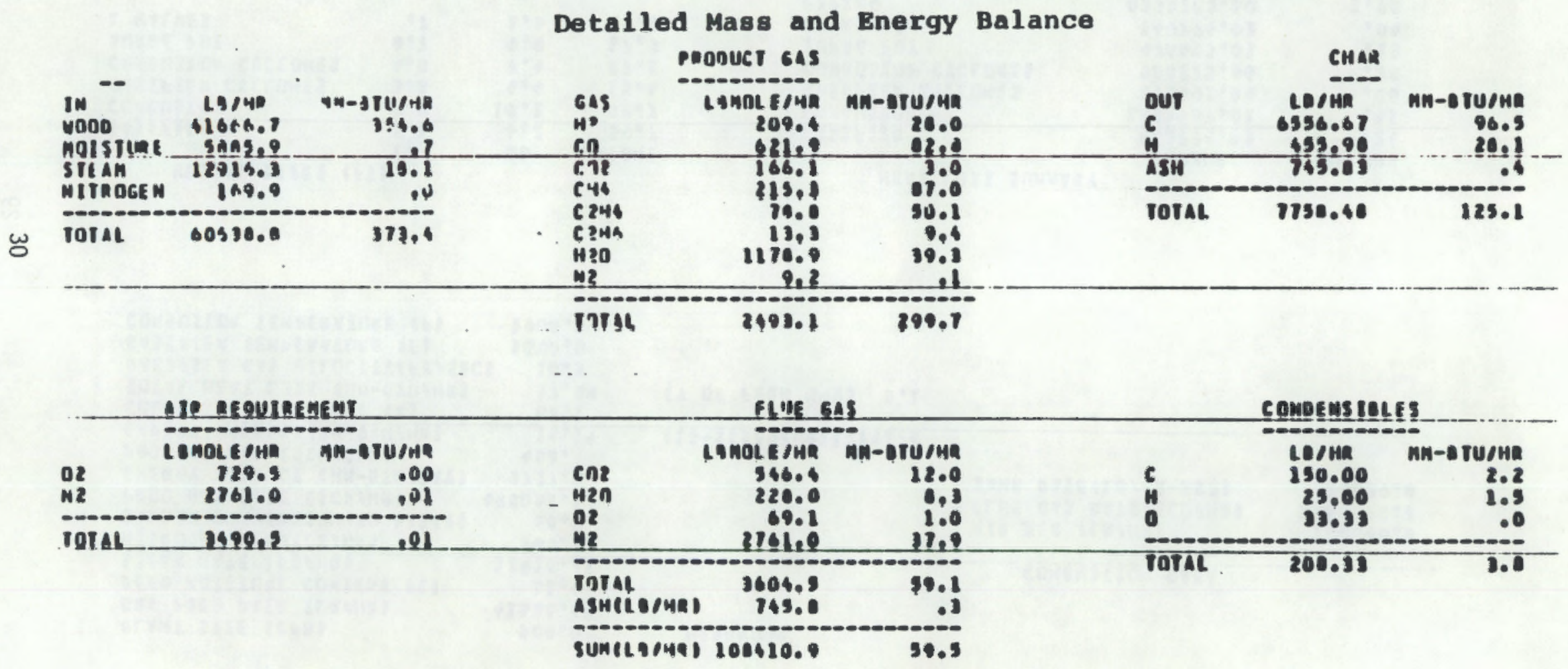

FIGURE 10. (continued) 
DETAILTE MASS ANO ENE:RGY DAL.ANCE.
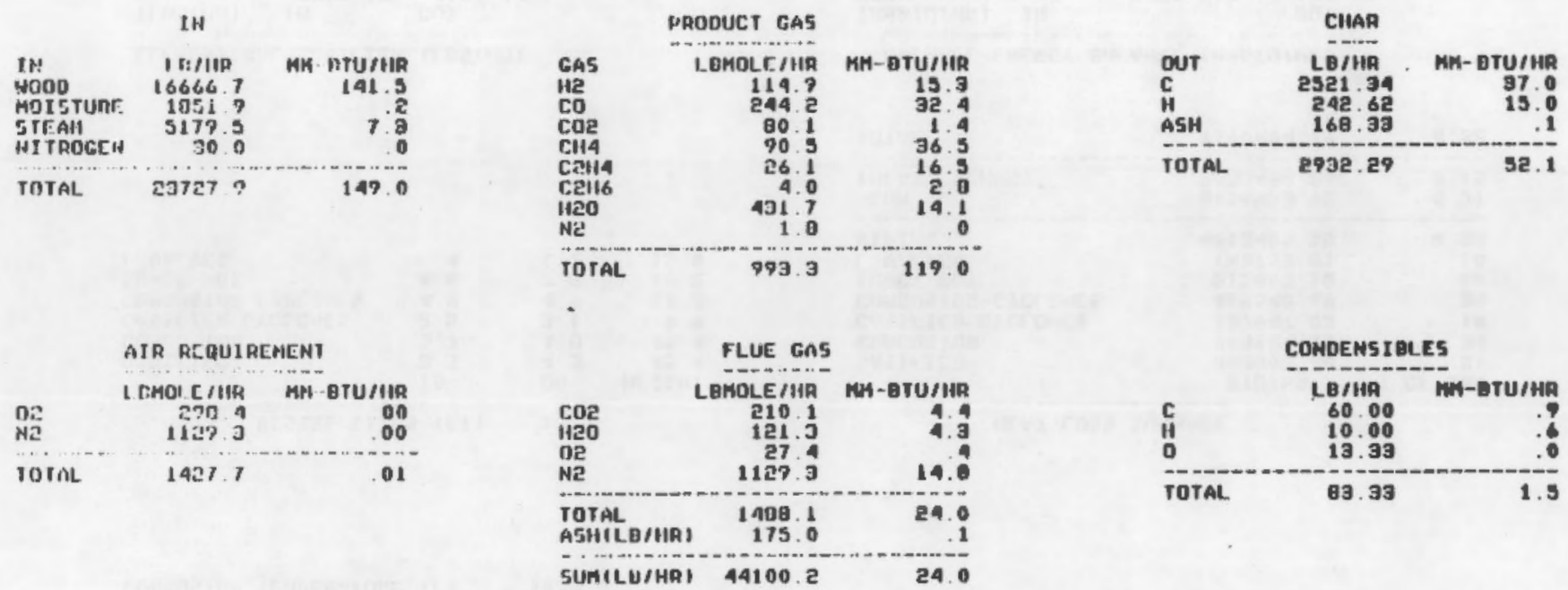

FIGURE 11. MASS AND ENERGY BALANCE FOR A 200 TPD PLANT USING SOFTWOOD AS THE FEEDSTOCK 
$X X X X$ MASS AND EHEAGY BMLAHCE SUMMAAY FOR FOAEST AESIDUE GASIFICATIOH MOOEL XXXX

Case 1

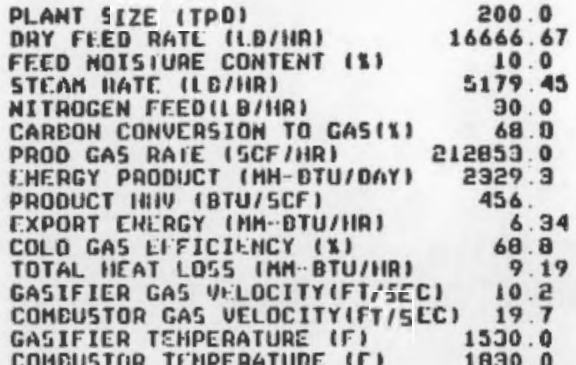

Sor TWOOD

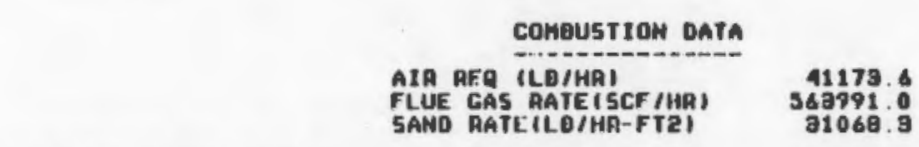

(LU-5TEAH/HRI 4468.0

IX OF FECD HHUI B.S

FLUE GAS RATE ISCF IHA
SAND RATEILO/HA-FT2)

91068.9

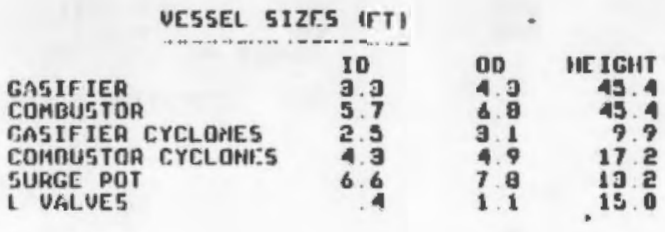

\begin{tabular}{|c|c|c|}
\hline $\begin{array}{l}\text { GASIFIER } \\
\text { COHEUSTDA } \\
\text { GASIFIER CYCLONES } \\
\text { COHEUSTOR CYCLONCS } \\
\text { SUAGE POT } \\
L \text { VALLUES } \\
\text { PIPIHG }\end{array}$ & 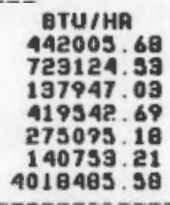 & 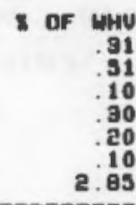 \\
\hline $\begin{array}{l}\text { SUH } \\
\text { IIIF:AT EXCHHGI }\end{array}$ & $\begin{array}{l}4156758.92 \\
3039450.86\end{array}$ & A. \\
\hline Total. & 9190404.79 & 6.52 \\
\hline
\end{tabular}

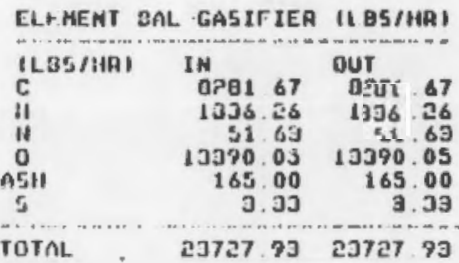

OUEEALL ENERGY BALANCE (MKBTU/HA)

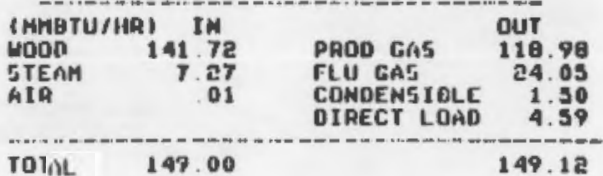

FIGURE 11. (continued) 
have a major influence on process performance, heat loss sensitivity to plant size was examined. Figure 12 presents a graph of heat loss versus plant size. From this, it appears that a plant smaller than about 100 tons per day would be expected to have "excessive" heat losses.

ECONOMIC EVALUATION

Conceptual process designs, based upon experimental results in the 6- and 10-inch units, have been made. These conceptual designs indicate that the Battelle system is readily adaptable for use at an existing industrial site due to the very compact nature of the system. For example, a 200-ton-per-day (dry wood) plant with all auxiliary equipment, except wood storage, would be contained within a $35^{\prime} \times 40^{\prime}$ area.

Figure 13 shows a typical conceptual plant layout. Based upon this layout, a first cut at estimating both capital and operating costs and an effective selling price for the medium Btu fuel gas has been made. In the evaluation, as would most likely be the case for commercial use of the technology, it was assumed that the wood gasification plant would be located at an existing industrial site. As a result, much of the grass-roots type equipment such as control room buildings, and utilities are assumed to be in place and only need to be expanded for the gasification plant.

The gasifier vessel for a 200-ton-per-day plant is 3.3 feet in diameter, while the combustor is 5.7 feet in diameter. A gasifier of this size utilizing softwood produces 100 million Btu per hour of medium Btu product gas.

Investment and operating costs are briefly summarized below for a gasification plant incorporated into an existing industrial plant site.

Prel iminary Economic Summary - $100 \mathrm{MM} \mathrm{Btu/Hr}$ Biomass Gasification Plant

Total Installed Equipment Cost Annual Operating Cost (Excluding Wood)

$=\$ 2,980,000$ Contribution of Wood to Gas Price,
(\$/MM Btu of Cooled Cleaned Product Gas) $=\frac{\$ / \text { dry ton }}{11.4}$ 


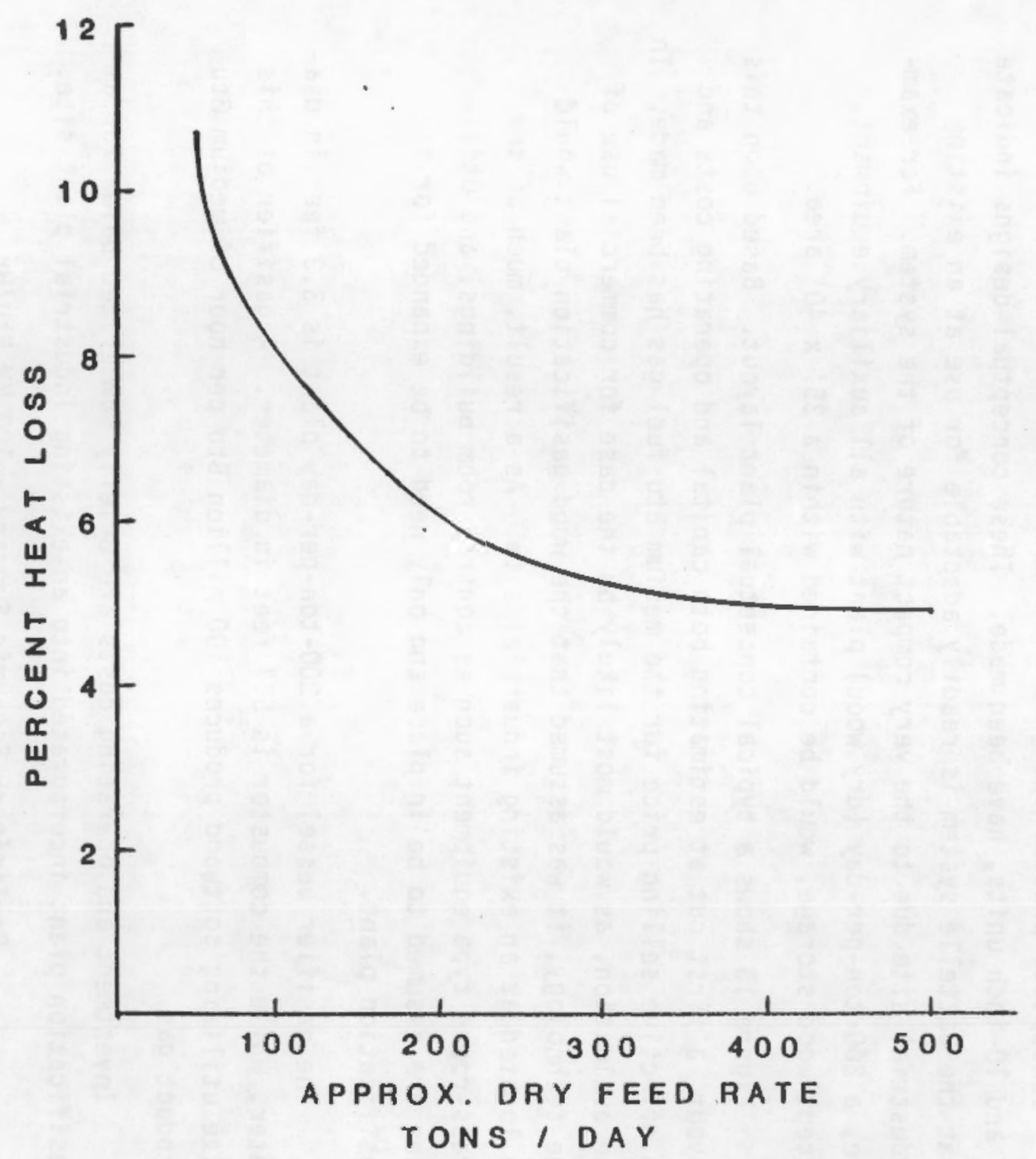

FIGURE 12. HEAT LOSS INCREASES SIGNIFICANTLY IN SMALLER REACTORS 

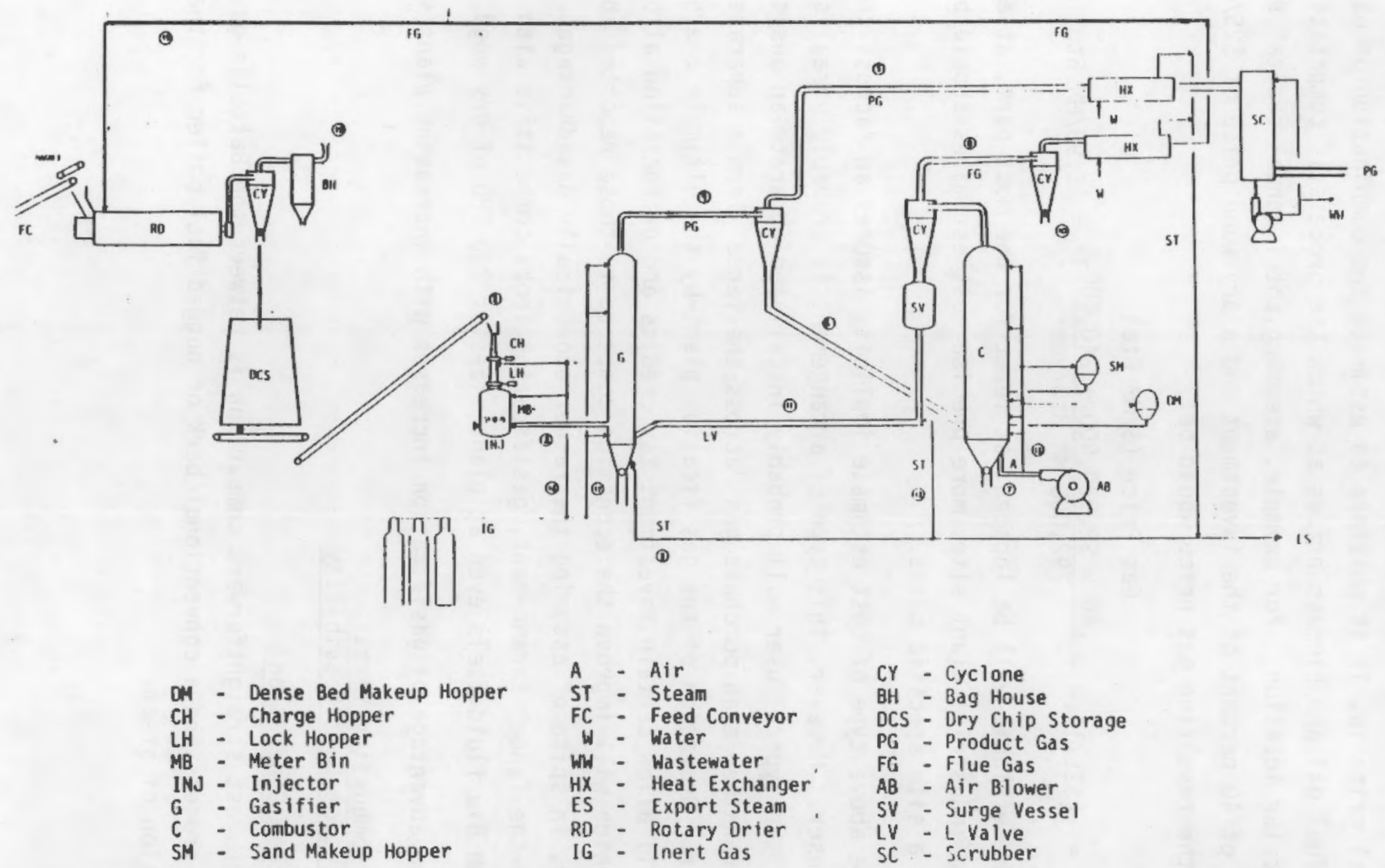

CY - Cyclone

BH - Bag House

DCS - Dry Chip Storage

$P G$ - Product Gas

FG - Flue Gas

$A B$ - Air Blower

SV - Surge Vessel

LV - L Valve

FIGURE 13. CONCEPTUAL PLANT LAYOUT 
Thus, with the above cost parameters and a company's internal financial criteria, it is possible to estimate the combination of natural gas or fuel oil and biomass prices at which the process is competitive in a particular location. For example, assuming total annual capital related charges of 40 percent of the investment and a dry wood price of $\$ 25 /$ ton (dry), the resulting gas price would be:

$$
\begin{gathered}
\text { Gas Price ( } \$ / \text { MM Btu) } \\
=\left[\$ 25 / 11.4+\frac{.40 \times \$ 2,980,000+240,000}{792,000 \text { MM Btu/year }}\right]=\$ 3.99 / \mathrm{MM} \mathrm{Btu}
\end{gathered}
$$

Since these plants will be located, at least for the most part, at an existing industrial plant site, more precise cost estimates should be made on a site specific basis.

The above type of cost estimate implicity assumes an "across-thefence" user. However, this type of arrangement is probably unrealistic in that the typical user will probably install and oprerate an onsite gasifier rather than purchase gas "across-the-fence" from a separate operator. Operation of the gasification plant by the ultimate energy user will allow certain investment tax credits and depreciation allowances which will improve the economics compared to those reported above. However, in spite of assuming the rather economically disadvantageous "across-the-fence" arrangement, gasification looks competitive with $\$ 4.50 / M M$ Btu fluid fuels even at plant sizes of 200 TPD of dry wood.

The advantage of gasification increases with increasing plant size.

Direct Combustion Versus Gasification-Cost Feasibility

\section{Steam Generation}

The most straightforward comparison is between the Battelle gasification process and a conventional bark or hogged fuel boiler foi the production of steam. 
In the Battelle gasification process, a portion of the steam is generated by the hot combustion gas prior to using the gas to dry the incoming wood. The product gas, after generating enough steam to satisfy gasifier feed requirements, is cooled and quenched and the $450 \mathrm{Btu} / \mathrm{scf}$ product gas is then burned in a conventional gas-fired boiler. The investment requirements and performance, as measured by net steam production for both of these options, are compared in Table 4. The basis for comparison is 200 TPD of dry wood to both facilities.

The themal efficiency for a conventional wood boiler using 40 percent ${ }^{(3)}$ wood fuel at an excess air level of 25 percent was assumed to be 72 percent. In practice excess air levels of 40 to 50 percent are not uncommon resulting in even lower efficiencies. In addition, the relatively large grate area required increases system heat losses per unit of wood fed. For example, the relative cross-section of the grate area of a conventional combustor is compared with the cross-sectional area of a Battelle biomass gasification system in Figure 14 .

Performance of the Battelle gasifier was based on heat losses calculated from a design model. The thermal efficiency in going to a cooledclean gas for the Battelle system is approximately 68 percent. The cooled gas is then burned in a conventional natural gas design package boiler, which typically has an efficiency of 85 percent.

With these assumptions, the steam production per unit of wood consumed is approximately 15 percent higher for combustion than gasification. However, the cost of the gasifier system plus package boiler is only one-third that of the conventional wood boiler!

The reason for the difference in capital investment is due mainly to the compactness of the biomass gasification system and a natural gas packaged boiler compared to conventional moving grate wood boiler.

\section{Electricity Cogeneration}

As mentioned above, industry is becoming increasingly interested in cogeneration. The conversion of wood and other biomass products to medium-Btu gas offers an alternative to using natural gas or petroleumderived fuels or direct combustion with a steam turbine. Therefore, it 
TABLE 4. GASIFICATION VERSUS DIRECT COMBUSTION FOR STEAM PRODUCTION

$\begin{array}{lccc}\text { Wood Rate (dry tons/day) } & \begin{array}{c}\text { Battelle } \\ \text { Gasification }\end{array} & \begin{array}{c}\text { Conventional } \\ \text { Wood Boiler }\end{array} \\ \text { Capital Investment }(\$ \mathrm{~mm}) & 200 & & 200 \\ \text { Steam Production Rate }(\mathrm{lb} / \mathrm{hr}) & 3.75 & & 11.0\end{array}$




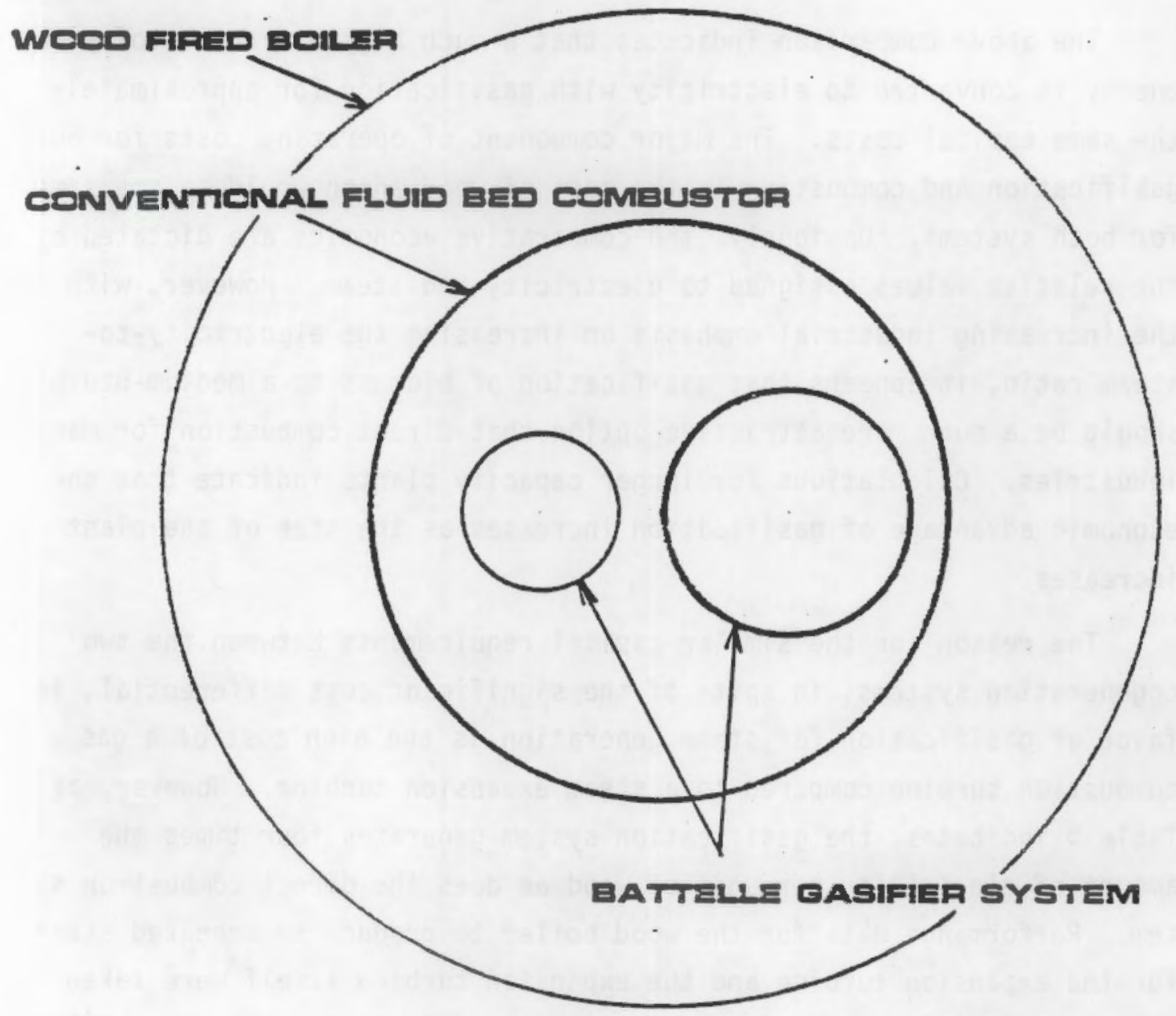

FIGURE 14. NEW TECHNOLOGY RESULTS IN MORE COMPACT EQUIPMENT 
is interesting to compare how gasification compares with direct combustion for cogeneration of electricity and steam. The results of this comparison are summarized in Table 5 for a plant utilizing 200 TPD of dry wood. As one might suspect, from the previous comparison between gasification and combustion for steam generation, gasification should show a significant advantage for generation of electrical power.

The above comparison indicates that a much higher fraction of wood energy is converted to electricity with gasification for approximately the same capital costs. The major component of operating costs for both gasification and combustion is the cost of wood which would be the same for both systems. Obviously, the comparative economics are dictated by the relative values assigned to electricity and steam. However, with the increasing industrial emphasis on increasing the electricity-tosteam ratio, it appears that gasification of biomass to a medium-Btu gas should be a much more attractive option that direct combustion for many industries. Calculations for larger capacity plants indicate that the economic advantage of gasification increases as the size of the plant increases.

The reason for the similar capital requirements between the two cogeneration systems, in spite of the significant cost differential, in favor of gasification for steam generation is the high cost of a gas combustion turbine compared to a steam expansion turbine. However, as Table 5 indicates, the gasification system generates four times the amount of electricity per unit of wood as does the direct combustion system. Performance data for the wood boiler to produce superheated steam for the expansion turbine and the expansion turbine itself were taken from Reference (5), which also provided the data on the gas combustion turbine used to evaluate gasifier performance.

\section{TECHNOLOGY TRANSFER}

Because of the potentially attractive economics, there has been considerable industrial interest in this technology. Riley Stoker, who is Battelle's U.S. licensee for multi-solid fluid-bed combustion technology, is working with Battelle to develop conceptual gasification system 
TABLE 5. GASIFICATION VERSUS DIRECT COMBUSTION FOR COGENERATION

\begin{tabular}{|c|c|}
\hline $\begin{array}{c}\text { Battelle } \\
\text { Gasification }\end{array}$ & $\begin{array}{l}\text { Conventional } \\
\text { Wood Boiler }\end{array}$ \\
\hline 200 & 200 \\
\hline 8,100 & 2,100 \\
\hline 50.000 & 66,000 \\
\hline 12.4 & 11.8 \\
\hline
\end{tabular}


designs for various industrial applications. We are hopeful that discussions currently underway will lead to a cost-shared scale-up of this technology.

CONCLUSIONS

Most importantly, results from this program have shown that medium Btu gas from wood can be competitive in today's energy market. Conclusions of experimental work in the Battelle's high-throughput gasifier PRU indicate that:

- The system can be scaled up without any change in product gas composition and demonstrates that higher carbon conversions are achieved at comparable reaction conditions in the larger reactor.

- A medium-Btu gas can be produced from biomass in very compact reactor systems.

- A wide range of physically diverse feedstocks can be gasified without preparation.

- The heating value of the dry gas is constant regardless of wood moisture level.

- No by-product char or tar are produced. (Since there is a separate high-temperature combustor, any tar separated from the gas wood be injected into the combustor.) 


\section{REFERENCES}

1. Feldmann, H. F., M. A. Paisley, D. W. Folsom, B. C. Kin, October 31, 1981, "Conversion of Forest Residues to a Methane-Rich Gas in a High-Throughput Gasifier", Summary Report.

2. Feldmann, H. F., M. A. Paisley, H. R. Appelbaum, March 16-17, 1983, "Gasification of Forest Residues in a High-Throughput Gasifier", 15th Biomass Themochemical Conversion Contractor's Meeting, Atlanta, Georgia.

3. Tinderman, E. M., et a1, September, 1980, "Technical \& Economic Evaluation of Blomass Utilization Processes Technical Report No. 1." Stanford Research Institute, DOE/ET/20605-T4.

4. Oak Ridge National Laboratory, "Handbook of Industrial Cogeneration", Oak Ridge National Lab and TRW, DOE/TIC-11605, October, 1981.

5. Miles, T., "Biomass Preparation for Thermochemical Conversion", Apri] 12-13, 1983, 1st European Workshop on Thermochemical Processing of Biomass, Birmingham, U.K. 


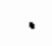


No. of

Coples

OFFSITE

Simon Friedrich

B1onass Energy Technology Division

Forrestal Bullding (CE-321)

U.S. Department of Energy

1000 Independence Avenue

Wash1ngton, DC 20585

30 DOE Technical Information Center

Onsite

DOE RAchland Operations

D. R. Segna

10 Pacif1c Northwest Laboratory

G. F. Schiefelbein

D. J. Stevens

M. A. Gerber

Publishing Coordination (2)

Technical Information (5) 
$y$ 